\title{
Werner Syndrome Protein Expression in Breast Cancer
}

\author{
Constantinos Savva, ${ }^{1}$ Maaz Sadiq, ${ }^{1}$ Omar Sheikh, ${ }^{1}$ Syed Karim, ${ }^{1}$ Sachin Trivedi,${ }^{1}$ \\ Andrew R. Green, ${ }^{3}$ Emad A. Rakha, ${ }^{3}$ Srinivasan Madhusudan, ${ }^{1,2}$ Arvind Arora ${ }^{1,2}$
}

\section{Abstract}

\begin{abstract}
Werner protein (WRN) is a DNA helicase involved in genomic stability and commonly inactivated in breast tumors. Its clinicopathologic significance was investigated in a cohort of clinically annotated series of sporadic $(n=1650)$ and BRCA-mutated $(n=75)$ invasive breast tumors. Low WRN expression was associated with worse survival and aggressive molecular phenotype. Low WRN expression in topoisomerase-l-overexpressed tumors was also associated with poor survival. These findings can be used to optimize personalized treatment. Introduction: Werner protein (WRN) plays an important role in DNA repair, replication, transcription, and consequently genomic stability via its DNA-helicase and exonuclease activity. Loss of function of WRN is associated with Werner syndrome (WS), which is characterized by premature aging and cancer predisposition. Malignancies that are commonly linked to WS are thyroid carcinoma, melanoma, breast cancer, meningioma, and soft tissue and bone sarcomas. Currently, the clinicopathologic significance of WRN in breast cancer is largely unknown. Patients and Methods: We investigated the clinicopathologic and prognostic significance of WRN protein expression in a cohort of clinically annotated series of sporadic $(n=1650)$ and BRCA-mutated $(n=75)$ invasive breast cancers. We correlated WRN protein expression to clinicopathologic characteristics, DNA repair protein expression, and survival outcomes. Results: There is strong evidence of association between low nuclear and cytoplasmic WRN co-expression and low levels of KU70/KU80, DNA-PK, DNA Pol-B, CKD18, cytoplasmic RECQL4, and nuclear BLM protein expression (adjusted $P$-values $<.05)$. Tumors with low nuclear or cytoplasmic WRN expression have worse overall breast cancer-specific survival (BCSS) (adjusted $P$-values $<.05)$. In topoisomerase I overexpressed tumors, low WRN nuclear expression was associated with poor BCSS $(P$-value $<.05)$. In BRCA-mutated tumors, low WRN cytoplasmic expression conferred shortest BCSS $(P<.05)$. Conclusions: Low WRN protein expression is associated with poor BCSS in patients with breast cancer. This can be used to optimize the risk stratification for personalized treatment.
\end{abstract}

Clinical Breast Cancer, Vol. m, No. m, m-m @ 2020 Elsevier Inc. All rights reserved.

Keywords: Biomarker, Breast Cancer, Helicase, Werner Syndrome Protein, WRN

\section{Introduction}

Werner (WRN) enzyme, also known as Recombinase Q like helicase 2 (RECQL2), has a DNA-helicase and exonuclease activity towards double-stranded DNA. ${ }^{1,2}$ The gene that encodes WRN protein is located in chromosome $8 \mathrm{p} 12$, and its role is to unwind

${ }^{1}$ Department of Oncology, Nottingham University Hospitals, Nottingham, UK

${ }^{2}$ Translational Oncology, Nottingham Breast Cancer Research Centre, Division

of Cancer and Stem Cells, School of Medicine, University of Nottingham, Nottingham, UK

${ }^{3}$ Department of Pathology, School of Medicine, University of Nottingham, Nottingham, UK

Submitted: Apr 18, 2020; Revised: Jul 9, 2020; Accepted: Jul 16, 2020

Address for correspondence: Dr. Arvind Arora, MBBS, MSc, DM, School of Medicine, University of Nottingham, University Hospitals of Nottingham NHS Trust City Hospital Campus, NG5 1PB

E-mail contact: arvind.arora1@nottingham.ac.uk the DNA and remove abnormal structures in an ATP-dependent and directionally specific manner. ${ }^{1,3,4}$ WRN protein has been shown to play an important role in DNA repair, replication, transcription, telomere maintenance, and, consequently, genomic stability. ${ }^{1,5,6}$ WRN co-localizes and shows direct interaction with topoisomerase I (TOPO I). WRN enhances the ability of TOPO I to relax negatively supercoiled DNA.

Mutations in the human WRN gene leading to the loss of WRN gene product are associated with Werner syndrome (WS). ${ }^{3} \mathrm{WS}$ is a rare autosomal recessive disease that is characterized by chromosomal instability, premature aging, and propensity to malignancies. ${ }^{1,8}$ The most common neoplasms in patients with WS are soft tissue sarcoma, osteosarcoma, thyroid cancer, malignant melanoma, breast cancer, benign meningioma, and myeloid disorders. ${ }^{8}$ Frequent molecular alterations that are seen in WS include nonsense, splicing or frameshift mutations, extensive deletions, 


\section{Werner Syndrome Protein in Breast Cancer}

inversions, and reciprocal translocations, with missense mutations being uncommon. ${ }^{9-11}$ Hence, the involvement of WRN in genome stability makes WRN gene function as a tumor-suppressor gene. ${ }^{12}$

RECQ helicases have a highly conserved RECQ C-terminal group that interacts with DNA damage response proteins. ${ }^{1,13,14}$ Knockout of WRN in primary fibroblasts using RNA interference led to increased oxidative DNA damage and early cellular senescence, indicating that WRN regulates oxidative stress homeostasis and DNA repair. ${ }^{15}$ This was supported by a study by Opresko et al, who demonstrated that deletion of WRN resulted in growth arrest at G2/ $\mathrm{M}$ cell cycle phases, DNA damage, and increased tumor cell death rate. ${ }^{13}$ Additionally, the surviving proliferative clones overexpressed WRN protein, which indicates that WRN plays an important role not only in carcinogenesis but also in tumor growth. ${ }^{16}$

To date, there is no clear evidence about the clinicopathologic and prognostic significance of WRN protein in breast cancer. In this study, we investigated the clinicopathologic and prognostic significance of WRN protein expression in patients with invasive breast cancer.

\section{Patients and Methods Tissue Culture and Western Blot Analysis}

Western blot analysis was used to evaluate the specificity of antiWRN antibody before using them for immunohistochemistry (IHC). WRN protein expression was assessed in 4 breast cancer cell lines: MCF7, MDA-MB-231, MDA-MB-436, and MDA-MB-468. Cell lines were purchased from American Type Culture Collection (ATCC, Manassas, VA). MDA-MB-436 and MDA-MB-468 cells were cultured in Minimum Essential amino acids Medium (Sigma), supplemented with $1 \%$ L-glutamine and $1 \%$ non-essential amino acids. MCF-7 and MDA-MB-231 cells were grown in RPMI medium (Sigma). All media were supplemented with 10\% FBS (Sigma), $5 \mathrm{~mL}$ of $1 \%$ penicillin/streptomycin $(10,000$ units penicillin and $10 \mathrm{mg}$ streptomycin/mL; Sigma). All cell lines were maintained in a humidified incubator at $37^{\circ} \mathrm{C}$ with $5 \%$ carbon dioxide and grown as an adherent culture.

Protein samples were prepared by lysing cells in RIPA buffer (Sigma-Aldrich) containing protease inhibitor (Sigma) and phosphatase inhibitor cocktail 1 and 2 (Sigma). Samples were run on SDS-PAGE gel (4\%-12\%) bis-tris. The antibodies used were antiWRN rabbit polyclonal antibody (Novus Biological, cat. no. NBP1-87143) at 1:1500 dilution, and anti- $\beta$-actin mouse monoclonal antibody (Sigma, cat. no. A2228 Clone AC-74) at 1:10,000 dilution. All equipment and reagents for Western blot were purchased from Thermo Fisher Scientific except for the protein standard (Precision Plus Protein All Blue Pre-stained Protein Standard, BioRad) and the secondary antibody solution (IRDye 800CW Donkey Anti-Rabbit IgG and IRDye 680CW Donkey Anti-Mouse IgG, Licor, Biosciences). Protein detection and quantification were determined by scanning the membranes on LicorOdyssey's scanner (Licor, Biosciences) at the predefined intensity fluorescence.

\section{Patient Selection for Protein Data}

Comprehensive evaluation of the protein expression of WRN in breast cancer was performed in a consecutive series of sporadic $(\mathrm{n}=1650)$ and BRCA-mutated $(\mathrm{n}=75)$ invasive breast tumors.
A total of 1650 unselected primary operable (stage I-III) sporadic invasive breast carcinomas from patients aged $\leq 70$ years who were diagnosed between 1986 and 1999 were included in the Nottingham Tenovus Primary Breast Cancer series. Women older than 70 years were excluded from the study because of the increased confounding factor of death from other causes and because primary treatment protocols for these patients often differed from those for younger women. Patients diagnosed before 1986 and after 1999 have been excluded because major changes in diagnosis and treatment were applied to patients before and after these time points. The patients' clinical history and tumor characteristics including family history and outcomes were obtained from the database that is prospectively maintained. Patient demographics are summarized in Supplemental Table 1 (in the online version). This is a well-characterized series of patients with long-term follow-up that have been investigated in a wide range of biomarker studies. ${ }^{17-19}$

Genetic testing for BRCA1 and BRCA2 germline mutations was performed in those patients with breast cancer from the Nottingham Tenovus series who were deemed to be a high risk of being a carrier (young age $<45$ years; triple negative breast cancers or family history of breast and/or ovarian cancer). Seventy-five confirmed germline deficient breast cancer tumors for BRCA1 or BRCA2 were identified and included into an independent BRCA-mutated cohort. Supplemental Table 2 (in the online version) summarizes the baseline characteristics of the BRCA-mutated cohort.

All patients were treated in a uniform way in a single institution with standard surgery (mastectomy or wide local excision), followed by radiotherapy. Prior to 1989 , patients did not receive systemic adjuvant treatment (AT). After 1989, AT was scheduled based on prognostic and predictive factor status, including Nottingham Prognostic Index (NPI), estrogen receptor- $\alpha(E R-\alpha)$ status, and menopausal status. Patients with NPI scores of $<3.4$ (low risk) did not receive AT. In pre-menopausal patients with NPI scores of $\geq 3.4$ (high risk), classical CMF (cyclophosphamide $100 \mathrm{mg} / \mathrm{m}^{2}$ orally on days $1-14$ or $600 \mathrm{mg} / \mathrm{m}^{2}$ intravenously (IV) on days 1 and 8 , methotrexate $40 \mathrm{mg} / \mathrm{m}^{2} \mathrm{IV}$ on days 1 and 8 , and 5-fluorouracil 600 $\mathrm{mg} / \mathrm{m}^{2} \mathrm{IV}$ on days 1 and 8 every 28 days) chemotherapy was given; patients with ER- $\alpha$-positive tumors were also offered endocrine therapy. Postmenopausal patients with NPI scores of $\geq 3.4$ and ER- $\alpha$ positivity were offered endocrine therapy, whereas ER- $\alpha$-negative patients received classical CMF chemotherapy. The median follow-up was 111 months (range, 1-233 months). Survival data, including breast cancer-specific survival (BCSS), disease-free survival (DFS), and development of loco-regional and distant metastases (DMs), were maintained on a prospective basis. DFS was defined as the number of months from diagnosis to the occurrence of local recurrence, local lymph node (LN) relapse, or DM relapse. BCSS was defined as the number of months from diagnosis to the occurrence of BC-related death. Local recurrence-free survival was defined as the number of months from diagnosis to the occurrence of local recurrence. DM-free survival was defined as the number of months from diagnosis to the occurrence of DM relapse. Survival was censored if the patient was still alive at the time of analysis, lost to follow-up, or died from other causes.

This retrospective study was performed on formalin-fixed paraffin-embedded (FFPE) archival tumor tissues collected immediately after surgery prior to any adjuvant oncologic treatment. The 
Figure 1 A, Western Blot of WRN Protein Expression in Breast Gancer Cell Lines. B, Relative WRN Protein Expression in Breast Gancer Cell Lines. C, Microphotographs of WRN Protein Expression in Normal Breast Tissue. D, Microphotographs of WRN Protein Expression in Breast Tumors

A

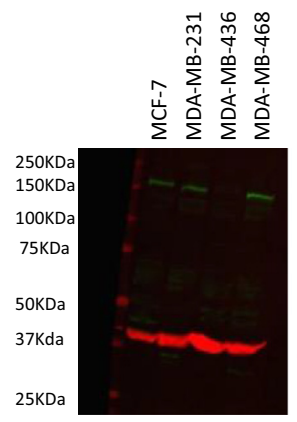

\section{B}

\section{C1}

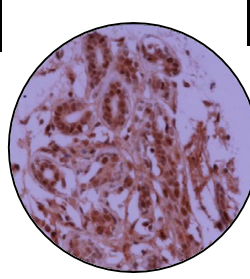

D1
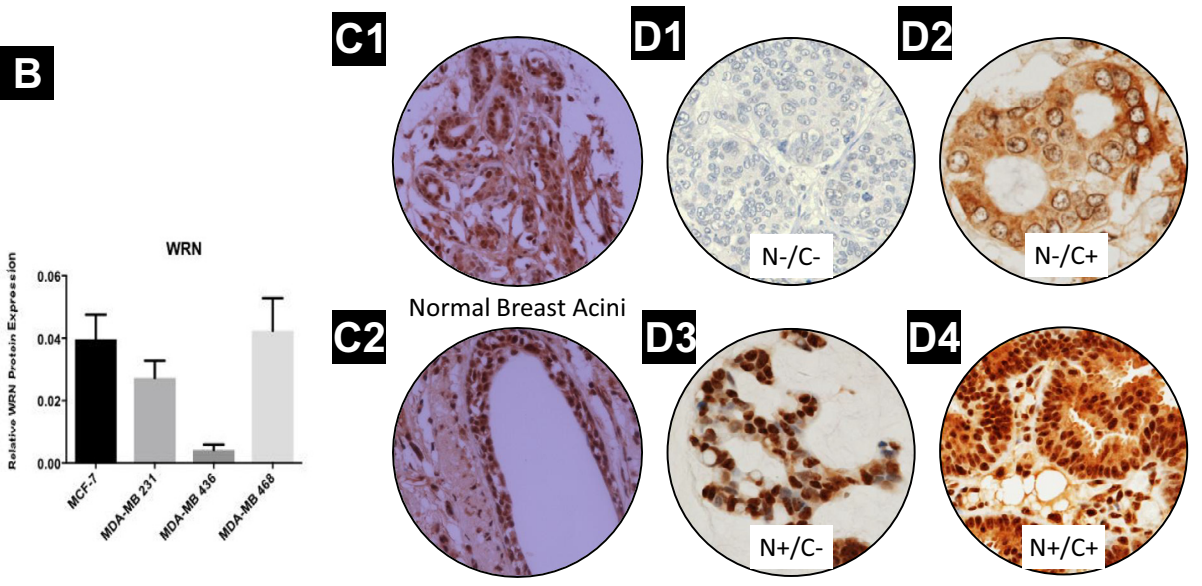

Normal Duct

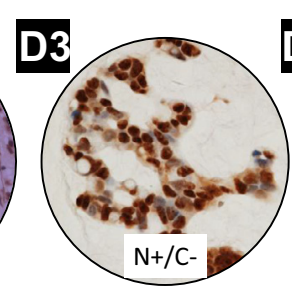

D4

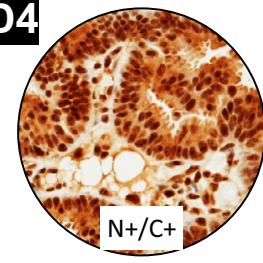

Abbreviations: $\mathrm{N}-/ \mathrm{C}-=$ nuclear negative and cytoplasmic negative; $\mathrm{N}+/ \mathrm{C}+=$ nuclear negative and cytoplasmic positive; $\mathrm{N}+/ \mathrm{C}-=$ nuclear positive and cytoplasmic negative; $\mathrm{N}-/ \mathrm{C}+=$ nuclear negative and cytoplasmic positive; WRN = Werner protein.

tissue blocks were stored in a secure, purpose-built facility in Nottingham University Hospitals NHS Trust, which is accessible to only authorized Tissue Bank staff according to the National Health Service Research Authority guidelines. Representative tumor tissues were prepared as tissue microarrays (TMAs).

Tumour Marker Prognostics Studies (REMARK) criteria, recommended by McShane et $\mathrm{al}^{20}{ }^{20}$ were followed throughout this project.

\section{TMAs and IHC}

Breast tumors were arrayed in TMAs constructed with 2 replicate $0.6-\mathrm{mm}$ cores from the center and periphery of the tumors. Optimal concentration and conditions for staining were ascertained for WRN antibody using the Thermo Scientific Shandon Sequenza chamber system (REF: 72110017), in combination with the Novolink Max Polymer Detection System (RE7280-K: 1250 tests), and the Leica Bond Primary Antibody Diluent (AR9352), each used according to the manufacturer's instructions (Leica Microsystems). Leica Autostainer XL machine was used to dewax and rehydrate the slides. The WRN antibody (rabbit antibody, polyclonal) was purchased from Novus Biological (NBP1-87143). Pre-treatment antigen retrieval was performed on the TMA sections using sodium citrate buffer ( $\mathrm{pH} \mathrm{6.0)}$ and heated for $20 \mathrm{~min}$ at $95^{\circ} \mathrm{C}$ in a microwave (Whirlpool JT359 Jet Chef $1000 \mathrm{~W}$ ). A set of slides were incubated at 18 hours at room temperature at a dilution of 1:100. Negative and positive (by omission of the primary antibody and IgG matched serum) controls were included in each run. The negative control ensured that all the staining was produced from the specific interaction between antibody and antigen.

\section{Evaluation of Immune Staining}

The tumor cores were evaluated by A.A. and an expert pathologist blinded to the clinicopathologic characteristics of patients. Whole field inspection of the core was scored, and intensities of nuclear and cytoplasmic staining were grouped as follows: $0=$ no staining, $1=$ weak staining, $2=$ moderate staining, and $3=$ strong staining. The percentage of each category was estimated (0\%-100\%). H-score (range, 0-300) was calculated by multiplying intensity of staining and percentage staining. Not all cores within the TMA were suitable for IHC analysis as some cores were missing or lacked tumor $(<15 \%$ tumor). As our data were non-parametric, we used the median cutoff to dichotomize $\mathrm{H}$ score expression of WRN into low and high expression. A median $\mathrm{H}$ score of $\geq 116$ was taken as the cutoff for high WRN nuclear expression, and a median $\mathrm{H}$-score of $\geq 20$ was taken as the cutoff for high WRN cytoplasmic expression.

\section{Statistical Analysis}

Data analysis was performed using SPSS (SPSS, version 22; Chicago, IL). Where appropriate, the Pearson $\chi^{2}$, Fisher exact, Student $t$, and 1-way analysis of variance tests were used. Cumulative survival probabilities were estimated using the Kaplan-Meier method, and differences between survival rates were tested for significance using the log-rank test. Multivariate analysis for survival was performed using the Cox proportional hazard model. The proportional hazards assumption was tested using standard log-log plots. Hazard ratios (HRs) and 95\% confidence intervals (95\% CIs) were estimated for each variable. All tests were 2-sided with a 95\% CI and a $P$ value $<.05$ considered significant. For multiple comparisons, $P$ values were adjusted according to Benjamini and Hochberg multiple $P$ value adjustment method. ${ }^{21}$

\section{Results}

\section{WRN Protein Expression in Breast Cancer}

We initially assessed WRN protein expression in a panel of breast cancer cell lines to confirm the specificity of antibodies for IHC in 
A

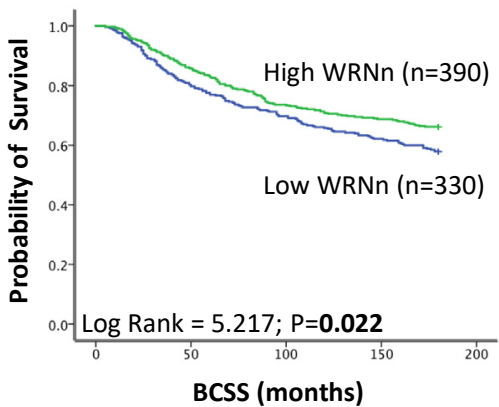

D

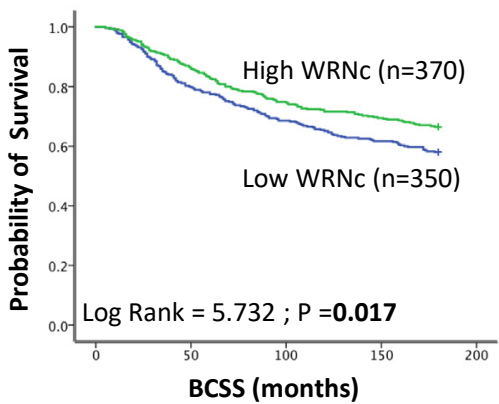

WRN protein nuclear expression

ER+ cohort; NPI>3.4

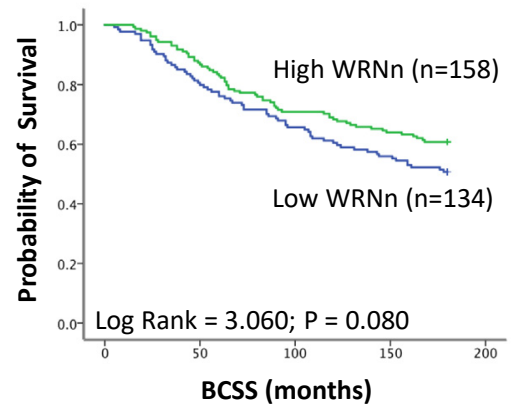

WRN protein cytoplasmic expression
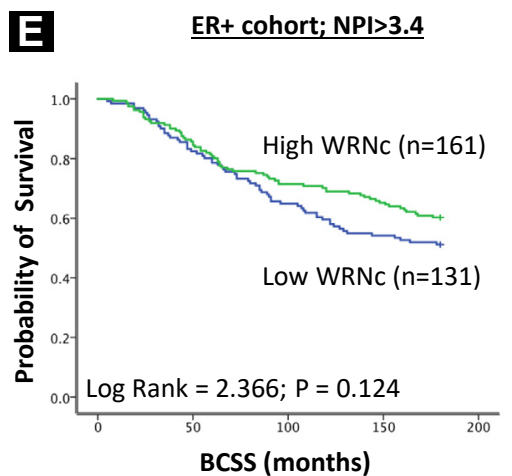

C

ER-cohort; NPI>3.4

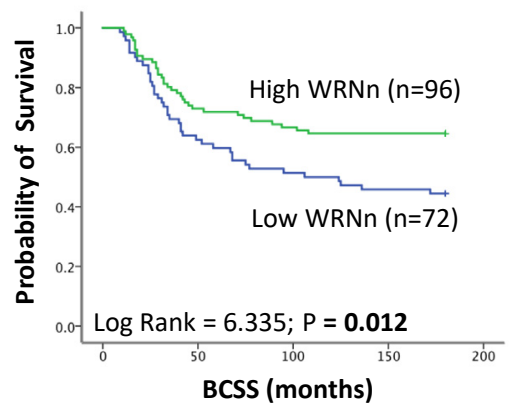

$\underline{\text { ER- cohort; NPI>3.4 }}$

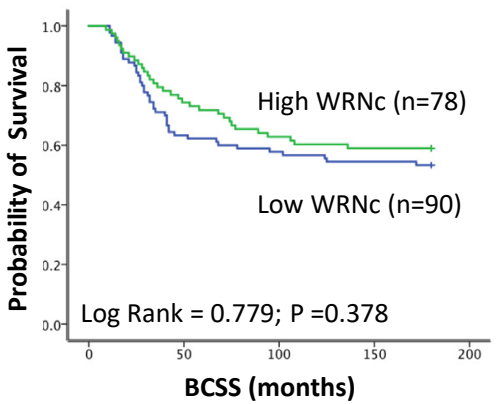

Abbreviations: BCSS = breast cancer-specific survival; ER = estrogen receptor; NPI = Nottingham Prognostic Index; WRN = Werner protein.

the current study. As shown in Figures $1 \mathrm{~A}$ and 1B, the anti-WRN antibody was not only specific but also showed that MCF-7, MDAMB231, and MDA-MB-468 have a robust expression of WRN protein. In contrast, MDA-MB-436 has the least WRN expression. We then proceeded to evaluate WRN protein levels in clinical breast carcinoma samples.

\section{WRN Nuclear Expression in Tumor Tissue is Lower Than Normal Breast Tissue}

We also evaluated the expression of WRN protein in 20 tumorassociated normal breast tissue slides. We observed both nuclear and cytoplasmic localization of WRN in normal and tumor breast tissue. We also observed that WRN nuclear expression was lower in tumor tissue (mean H-score, 116) as compared with normal breast tissue (mean H score, 220). For WRN cytoplasmic expression, the mean $\mathrm{H}$ score in tumor tissue was 20 as compared with a mean $\mathrm{H}$ score of 170 in normal breast tissue (Figures 1C1-2 and 1D1-4).

\section{WRN Protein Expression is Associated With Low Levels of DNA Repair Proteins in Breast Cancer}

A total of 933 sporadic tumors were suitable for WRN nuclear and 954 sporadic tumors for WRN cytoplasmic protein expression analyses. When we correlated WRN nuclear expression with other DNA repair proteins and regulators, low nuclear WRN was significantly associated with low KU70/KU80 levels $(P=.039)$, low DNA PKc $(P=.019)$, and low DNA Pol-b $(P=.019)$. In addition, reduced WRN protein expression was associated with low CDK18 levels $(P=.015)$. There was also a strong association with low expression levels of other DNA helicases, such as nuclear and cytoplasmic RECQL4 $(P$ values $<.05)$ and RECQL5 $(P=.013)$. In addition, when we correlated WRN cytoplasmic expression with other DNA repair proteins and regulators, low nuclear WRN cytoplasmic was significantly associated with low DNA PKc $(P=.039)$ and low nuclear BLM $(P=.026)$. Nevertheless, there was no statistically significant association between WRN nuclear or cytoplasmic expression and clinicopathologic features in breast cancer (Tables 1 and 2).

A total of 70 BRCA-mutated tumors were suitable for WRN nuclear and WRN cytoplasmic protein expression analyses. Similarly to the sporadic breast tumors, there was no evidence of association between WRN protein expression and clinicopathologic parameters in the BRCA-mutated cohort (see Supplemental Tables 3 and 4 in the online version).

WRN Nuclear and Cytoplasm Co-Expression is Associated With Low Levels of DNA Repair Proteins in Breast Cancer. A total of 954 sporadic tumors were suitable for WRN nuclear and cytoplasmic protein 
Constantinos Savva et al

Table 1 Werner Nuclear Protein Expression in Sporadic Breast Cancer

\begin{tabular}{|c|c|c|c|c|}
\hline & \multicolumn{2}{|c|}{ Werner Nuclear Protein Expression } & \multicolumn{2}{|c|}{$P$ Value } \\
\hline & Low, N (\%) & High, N (\%) & Unadjusted & Adjusted \\
\hline \multicolumn{5}{|l|}{ Pathologic parameters } \\
\hline Tumor size, $\mathrm{cm}^{\mathrm{a}}$ & & & .740 & .848 \\
\hline$<1(T 1 a+b)$ & $7(5.9)$ & $13(8.5)$ & & \\
\hline$>1-2(\mathrm{~T} 1 \mathrm{c})$ & $50(42.4)$ & $62(40.5)$ & & \\
\hline$>2-5$ (T2) & $60(50.8)$ & $75(49)$ & & \\
\hline$>5$ (Т3) & $1(0.8)$ & $3(2.0)$ & & \\
\hline Tumor stage & & & .330 & .585 \\
\hline 1 & $53(44.9)$ & $64(41.8)$ & & \\
\hline 2 & $48(40.7)$ & $74(48.4)$ & & \\
\hline 3 & $17(14.4)$ & $15(9.8)$ & & \\
\hline Tumor grade ${ }^{b}$ & & & .642 & .807 \\
\hline G1 & $6(5.1)$ & $5(3.3)$ & & \\
\hline G2 & $49(41.5)$ & $70(45.8)$ & & \\
\hline G3 & $63(53.4)$ & $78(51)$ & & \\
\hline Mitotic index & & & .785 & .850 \\
\hline M1 (low; mitoses < 10) & 33 (28.4) & $47(30.9)$ & & \\
\hline M2 (medium; mitoses 10-18) & $30(25.9)$ & $42(27.6)$ & & \\
\hline M3 (high; mitosis > 18) & $53(45.7)$ & $63(41.4)$ & & \\
\hline Tubule formation & & & .401 & .680 \\
\hline 1 (> 75\% of definite tubule) & $1(0.9)$ & $2(1.3)$ & & \\
\hline 2 (10\%-75\% definite tubule) & $40(34.5)$ & $41(27.0)$ & & \\
\hline 3 ( $<10 \%$ definite tubule) & $75(64.7)$ & $109(71.7)$ & & \\
\hline Pleomorphism & & & .462 & .667 \\
\hline 1 (small-regular uniform) & $1(0.9)$ & $1(0.7)$ & & \\
\hline 2 (moderate variation) & $42(36.2)$ & $66(43.7)$ & & \\
\hline 3 (marked variation) & $73(62.9)$ & $84(55.6)$ & & \\
\hline Tumor type & & & .730 & .862 \\
\hline IDC-NST & $70(59.8)$ & $86(56.6)$ & & \\
\hline Tubular carcinoma & 19 (16.2) & $22(14.1)$ & & \\
\hline \multicolumn{5}{|l|}{ Medullary carcinoma } \\
\hline ILC & 19 (16.2) & $33(21.7)$ & & \\
\hline \multicolumn{5}{|l|}{ Others } \\
\hline Mixed NST/lobular/special type & $9(7.7)$ & $11(7.2)$ & & \\
\hline Lymph node status & & & .530 & .712 \\
\hline Negative & $51(44.7)$ & $64(42.7)$ & & \\
\hline Positive (1-3) & $50(43.9)$ & $74(49.3)$ & & \\
\hline Positive (> 3) & $13(11.4)$ & $12(8.0)$ & & \\
\hline \multicolumn{5}{|l|}{ Aggressive phenotype } \\
\hline HER2 overexpression & & & .525 & .731 \\
\hline No & $105(91.3)$ & $141(93.4)$ & & \\
\hline Yes & $10(8.7)$ & $10(6.6)$ & & \\
\hline \multicolumn{5}{|l|}{ Triple negative } \\
\hline No & $103(87.3)$ & $123(80.4)$ & & \\
\hline Yes & $15(12.7)$ & $30(19.6)$ & .130 & .298 \\
\hline \multicolumn{5}{|l|}{$\mathrm{NPI}$} \\
\hline$\leq 3.4$ & $7(6.5)$ & $7(4.8)$ & & \\
\hline$>3.4$ & $100(93.5)$ & $140(95.2)$ & .539 & .700 \\
\hline
\end{tabular}




\section{Werner Syndrome Protein in Breast Cancer}

Table 1 Continued

\begin{tabular}{|c|c|c|c|c|}
\hline & \multicolumn{2}{|c|}{ Werner Nuclear Protein Expression } & \multicolumn{2}{|c|}{$P$ Value } \\
\hline & Low, N (\%) & High, N (\%) & Unadjusted & Adjusted \\
\hline \multicolumn{5}{|l|}{ Hormone receptors } \\
\hline \multicolumn{5}{|l|}{ ER } \\
\hline Negative & $110(26.3)$ & $139(27)$ & & \\
\hline Positive & $309(73.7)$ & $375(73)$ & .786 & .828 \\
\hline \multicolumn{5}{|l|}{$\mathrm{PgR}$} \\
\hline Negative & $34(29.6)$ & $33(22.6)$ & & \\
\hline Positive & $81(70.4)$ & $113(77.4)$ & .201 & .392 \\
\hline \multicolumn{5}{|l|}{ DNA repair proteins } \\
\hline ATM & & & .439 & .658 \\
\hline Low & $139(53.9)$ & $160(50.6)$ & & \\
\hline High & $119(46.1)$ & $156(49.4)$ & & \\
\hline ATR (Nuclear) & & & .025 & .886 \\
\hline Low & $75(59.1)$ & $102(46.6)$ & & \\
\hline High & $52(40.9)$ & $117(53.4)$ & & \\
\hline \multicolumn{5}{|l|}{ RAD51 (Cytoplasmic) } \\
\hline Low & $14(5.8)$ & $16(5.8)$ & & \\
\hline High & $228(94.2)$ & $259(94.2)$ & .987 & 38.49 \\
\hline RAD51 (Nuclear) & & & .033 & .107 \\
\hline Low & $139(57.2)$ & $132(47.8)$ & & \\
\hline High & $104(42.8)$ & $144(52.2)$ & & \\
\hline BRCA1 & & & .175 & .359 \\
\hline Low & 55 (17.5) & 57 (13.8) & & \\
\hline High & $260(82.5)$ & 356 (86.2) & & \\
\hline PARP1 & & & .413 & .671 \\
\hline Low & $173(53.1)$ & $196(50.0)$ & & \\
\hline High & $153(46.9)$ & $196(50.0)$ & & \\
\hline KU70/KU80 & & & $<.001$ & .039 \\
\hline Low & $62(23.3)$ & 34 (11.3) & & \\
\hline High & $204(76.7)$ & 267 (88.7) & & \\
\hline DNA PKC & & & .001 & .019 \\
\hline Low & $50(22.0)$ & 37 (11.9) & & \\
\hline High & $202(78.0)$ & $274(88.1)$ & & \\
\hline ERCC1 & & & .155 & .335 \\
\hline Low & $100(50.3)$ & $107(43.5)$ & & \\
\hline High & $99(49.7)$ & $139(56.5)$ & & \\
\hline XRCC1 & & & .053 & .137 \\
\hline Low & 62 (19.6) & $50(14.0)$ & & \\
\hline High & $255(80.4)$ & 307 (86.2) & & \\
\hline SMUG & & & .707 & .861 \\
\hline Low & $143(50.2)$ & $167(51.7)$ & & \\
\hline High & $142(49.8)$ & $156(48.3)$ & & \\
\hline \multicolumn{5}{|l|}{ DNA Pol-B } \\
\hline Low & 78 (22.3) & 55 (11.9) & & \\
\hline High & $272(77.7)$ & $346(86.3)$ & .002 & .019 \\
\hline FEN1 (Cytoplasmic) & & & .960 & 1.00 \\
\hline Low & $158(51.6)$ & $179(51.4)$ & & \\
\hline High & $148(48.4)$ & $169(48.6)$ & & \\
\hline
\end{tabular}


Constantinos Savva et al

Table 1 Continued

\begin{tabular}{|c|c|c|c|c|}
\hline & \multicolumn{2}{|c|}{ Werner Nuclear Protein Expression } & \multicolumn{2}{|c|}{$P$ Value } \\
\hline & Low, N (\%) & High, N (\%) & Unadjusted & Adjusted \\
\hline FEN1 (Nuclear) & & & & .834 \\
\hline Low & $225(73.5)$ & $252(72.4)$ & & \\
\hline High & $81(26.5)$ & $96(27.6)$ & .749 & \\
\hline \multicolumn{5}{|c|}{ Cell cycle and apoptosis regulators } \\
\hline P53 & & & .417 & .650 \\
\hline Low & $287(69.7)$ & $367(72.1)$ & & \\
\hline High & $125(30.3)$ & $142(27.9)$ & & \\
\hline CDK18 & & & .002 & .015 \\
\hline Low & $171(56.6)$ & $154(44.3)$ & & \\
\hline High & $131(43.4)$ & $194(55.7)$ & & \\
\hline Chk1 (Cytoplasmic) & & & .024 & .093 \\
\hline Low & $169(41.7)$ & $170(34.4)$ & & \\
\hline High & $236(58.3)$ & $324(65.6)$ & & \\
\hline Chk1 (Nuclear) & & & .218 & .404 \\
\hline Low & $346(85.4)$ & $407(82.4)$ & & \\
\hline High & $59(14.6)$ & $87(17.6)$ & & \\
\hline CHK2 & & & .035 & .105 \\
\hline Low & $63(26.6)$ & 56 (18.9) & & \\
\hline High & $174(73.4)$ & $240(81.1)$ & & \\
\hline RECQL5 (Nuclear) & & & $<.001$ & .013 \\
\hline Low & $175(56.6)$ & $142(39.1)$ & & \\
\hline High & $134(43.4)$ & $221(60.9)$ & & \\
\hline RECQL4 (Nuclear) & & & .010 & .048 \\
\hline Low & $177(66.6)$ & $179(56.1)$ & & \\
\hline High & 89 (33.5) & $140(43.9)$ & & \\
\hline RECQL4 (Cytoplasmic) & & & .002 & .013 \\
\hline Low & $146(55.1)$ & $134(42.3)$ & & \\
\hline High & $119(44.9)$ & $183(57.7)$ & & \\
\hline RECQL1 & & & .037 & .103 \\
\hline Low & $137(54.8)$ & $128(45.7)$ & & \\
\hline High & $113(45.2)$ & $152(54.3)$ & & \\
\hline BLM (Nuclear) & & & .118 & .287 \\
\hline Low & $100(29.8)$ & $90(24.5)$ & & \\
\hline High & $236(70.2)$ & $277(75.5)$ & & \\
\hline BLM (Cytoplasmic) & & & .017 & .073 \\
\hline Low & $255(75.9)$ & $246(67.8)$ & & \\
\hline High & $81(24.1)$ & $117(32.2)$ & & \\
\hline C-MYC & & & .845 & .867 \\
\hline Low & $140(48.1)$ & $131(47.3)$ & & \\
\hline High & $151(51.9)$ & $146(52.7)$ & & \\
\hline
\end{tabular}

Bold indicates statistically significant.

Unadjusted $P$ values were calculated using the Pearson $\chi^{2}$ test. The Fisher exact test was used to obtain $P$ values where one or more of cells has an expected frequency of 5 or less. Adjusted $P$ values were calculated using the Benjamini-Hochberg false discovery rate method to adjust for multiple testing.

Abbreviations: ER = estrogen receptor; HER2 = human epidermal growth factor receptor 2; IDC-NST = invasive carcinoma of no special type; ILC = invasive lobular carcinoma; NPI = Nottingham Prognostic Index; $\mathrm{PgR}=$ progesterone receptor; $\mathrm{WRN}=$ Werner protein

aTumor size as defined by TNM Classification of Malignant Tumours (8th edition).

${ }^{\mathrm{b}}$ Grade as defined by Nottingham Grading System. 


\section{Werner Syndrome Protein in Breast Cancer}

Table 2 Werner Cytoplasmic Protein Expression in Sporadic Breast Cancer

\begin{tabular}{|c|c|c|c|c|}
\hline & \multicolumn{2}{|c|}{ Werner Cytoplasmic Protein Expression } & \multicolumn{2}{|c|}{$P$ Value } \\
\hline & Low, N (\%) & High, N (\%) & Unadjusted & Adjusted \\
\hline \multicolumn{5}{|l|}{ Pathologic parameters } \\
\hline Tumor size, $\mathrm{cm}^{\mathrm{a}}$ & & & .432 & .673 \\
\hline$<1(\mathrm{~T} 1 \mathrm{a}+\mathrm{b})$ & $52(11.2)$ & $61(12.4)$ & & \\
\hline$>1-2(\mathrm{~T} 1 \mathrm{c})$ & $234(50.4)$ & $233(47.6)$ & & \\
\hline$>2-5$ (Т2) & $175(37.7)$ & $188(38.4)$ & & \\
\hline$>5$ (Т3) & $3(0.6)$ & $8(1.6)$ & & \\
\hline Tumor stage & & & .335 & .593 \\
\hline 1 & $300(64.7)$ & $304(61.9)$ & & \\
\hline 2 & $120(25.9)$ & $147(29.9)$ & & \\
\hline 3 & $44(9.5)$ & $40(8.1)$ & & \\
\hline Tumor grade $^{b}$ & & & .330 & .612 \\
\hline G1 & $83(17.9)$ & $84(17.1)$ & & \\
\hline G2 & $149(32.1)$ & $180(36.7)$ & & \\
\hline G3 & $232(50.0)$ & $227(46.2)$ & & \\
\hline Mitotic index & & & .213 & .639 \\
\hline M1 (low; mitoses < 10) & $158(35.7)$ & $191(39.7)$ & & \\
\hline M2 (medium; mitoses 10-18) & $72(16.3)$ & $87(18.1)$ & & \\
\hline M3 (high; mitosis > 18) & $212(48.0)$ & $203(42.2)$ & & \\
\hline Tubule formation & & & .926 & .976 \\
\hline 1 (> 75\% of definite tubule) & $24(5.4)$ & $28(5.8)$ & & \\
\hline 2 (10\%-75\% definite tubule) & $140(31.7)$ & $156(32.4)$ & & \\
\hline $3(<10 \%$ definite tubule) & $278(62.9)$ & $297(61.7)$ & & \\
\hline Pleomorphism & & & .123 & .533 \\
\hline 1 (small-regular uniform) & $15(3.4)$ & $8(1.7)$ & & \\
\hline 2 (moderate variation) & $166(37.7)$ & 202 (42.2) & & \\
\hline 3 (marked variation) & $259(58.9)$ & 269 (56.2) & & \\
\hline Tumor type & & & .079 & .385 \\
\hline IDC-NST & $261(57.1)$ & $269(55.6)$ & & \\
\hline Tubular carcinoma & $92(20.1)$ & $108(22.3)$ & & \\
\hline Medullary carcinoma & $18(3.9)$ & $5(1.0)$ & & \\
\hline ILC & $55(12.0)$ & $62(12.8)$ & & \\
\hline Others & $8(1.8)$ & $8(1.7)$ & & \\
\hline $\begin{array}{l}\text { Mixed NST/lobular/special } \\
\text { type }\end{array}$ & $23(5.0)$ & $32(6.6)$ & & \\
\hline Lymph node status & & & .253 & .616 \\
\hline Negative & $246(62.6)$ & $285(62.5)$ & & \\
\hline Positive (1-3) & $113(28.8)$ & $144(31.6)$ & & \\
\hline Positive (>3) & $34(8.7)$ & $27(5.9)$ & & \\
\hline \multicolumn{5}{|l|}{ Aggressive phenotype } \\
\hline HER2 overexpression & & & .266 & .546 \\
\hline No & $395(86.2)$ & $422(88.7)$ & & \\
\hline Yes & $63(13.8)$ & $54(11.3)$ & & \\
\hline Triple negative & & & .493 & .739 \\
\hline No & $393(84.0)$ & $405(82.3)$ & & \\
\hline Yes & $75(16.0)$ & $87(17.7)$ & & \\
\hline NPI & & & .986 & 38.45 \\
\hline$\leq 3.4$ & $146(33.0)$ & $155(33.0)$ & & \\
\hline$>3.4$ & $296(67.0)$ & $315(67.0)$ & & \\
\hline
\end{tabular}


Constantinos Savva et al

Table 2 Continued

\begin{tabular}{|c|c|c|c|c|}
\hline & \multicolumn{2}{|c|}{ Werner Cytoplasmic Protein Expression } & \multicolumn{2}{|c|}{$P$ Value } \\
\hline & Low, N (\%) & High, N (\%) & Unadjusted & Adjusted \\
\hline \multicolumn{5}{|l|}{ Hormone receptors } \\
\hline \multicolumn{5}{|l|}{ ER } \\
\hline Negative & $129(28.4)$ & $120(25.1)$ & & \\
\hline Positive & $326(71.6)$ & $358(74.9)$ & .262 & .567 \\
\hline \multicolumn{5}{|l|}{$\mathrm{PgR}$} \\
\hline Negative & $206(46.7)$ & $184(40.3)$ & & \\
\hline Positive & $235(53.3)$ & $273(59.7)$ & .051 & .331 \\
\hline \multicolumn{5}{|l|}{ DNA repair proteins } \\
\hline \multicolumn{5}{|l|}{ ATM } \\
\hline Low & $146(51.8)$ & $153(52.4)$ & & \\
\hline High & $136(48.2)$ & $139(47.6)$ & .881 & 1.01 \\
\hline ATR (Nuclear) & & & .619 & .832 \\
\hline Low & $78(52.7)$ & $99(50.0)$ & & \\
\hline High & $70(47.3)$ & $99(50.0)$ & & \\
\hline \multicolumn{5}{|l|}{ RAD51 (Cytoplasmic) } \\
\hline Low & $15(5.7)$ & $15(5.9)$ & & \\
\hline High & $249(94.3)$ & $238(94.1)$ & .904 & 1.007 \\
\hline RAD51 (Nuclear) & & & .002 & .078 \\
\hline Low & $156(58.9)$ & $115(45.3)$ & & \\
\hline High & $109(41.1)$ & $139(54.7)$ & & \\
\hline \multicolumn{5}{|l|}{ BRCA1 } \\
\hline Low & $63(17.9)$ & $49(13.0)$ & & \\
\hline High & $288(82.1)$ & $328(87.0)$ & .064 & .356 \\
\hline \multicolumn{5}{|l|}{ PARP1 } \\
\hline Low & $189(51.8)$ & $180(51.0)$ & & \\
\hline High & 176 (48.2) & $173(49.0)$ & .832 & 1.014 \\
\hline \multicolumn{5}{|l|}{ KU70/KU80 } \\
\hline Low & $54(18.7)$ & $42(15.1)$ & & \\
\hline High & $235(81.3)$ & $236(84.9)$ & .256 & .587 \\
\hline \multicolumn{5}{|l|}{ DNA PKC } \\
\hline Low & $60(21.5)$ & $34(11.7)$ & & \\
\hline High & $219(78.5)$ & $257(88.3)$ & .002 & .039 \\
\hline \multicolumn{5}{|l|}{ ERCC1 } \\
\hline Low & $106(46.9)$ & $101(46.1)$ & & \\
\hline High & $120(53.1)$ & $118(53.9)$ & .868 & 1.025 \\
\hline \multicolumn{5}{|l|}{ XRCC1 } \\
\hline Low & $58(17.4)$ & $54(15.9)$ & & \\
\hline High & $276(82.6)$ & $286(84.1)$ & .605 & .842 \\
\hline \multicolumn{5}{|l|}{ SMUG1 } \\
\hline Low & $79(25.2)$ & $65(22.0)$ & & \\
\hline High & $234(74.8)$ & $230(78.0)$ & .353 & .598 \\
\hline \multicolumn{5}{|l|}{ DNA POI-B } \\
\hline Low & $72(19.4)$ & $61(16.1)$ & & \\
\hline High & 300 (80.6) & 318 (83.9) & .242 & .629 \\
\hline FEN1 (Cytoplasmic) & & & .919 & .995 \\
\hline Low & $173(51.3)$ & $164(51.7)$ & & \\
\hline High & $164(48.7)$ & 153 (48.3) & & \\
\hline
\end{tabular}




\section{Werner Syndrome Protein in Breast Cancer}

Table 2 Continued

\begin{tabular}{|c|c|c|c|c|}
\hline & \multicolumn{2}{|c|}{ Werner Cytoplasmic Protein Expression } & \multicolumn{2}{|c|}{$P$ Value } \\
\hline & Low, N (\%) & High, N (\%) & Unadjusted & Adjusted \\
\hline FEN1 (Nuclear) & & & .504 & .728 \\
\hline Low & $242(71.8)$ & $235(74.1)$ & & \\
\hline High & $95(28.2)$ & $82(25.9)$ & & \\
\hline \multicolumn{5}{|c|}{ Cell cycle and apoptosis regulators } \\
\hline P53 & & & .131 & .510 \\
\hline Low & $312(68.7)$ & $342(73.2)$ & & \\
\hline High & $142(31.3)$ & $125(26.8)$ & & \\
\hline CDK18 & & & .272 & .530 \\
\hline Low & $169(52.2)$ & $156(47.9)$ & & \\
\hline High & $155(47.8)$ & $170(52.1)$ & & \\
\hline Chk1 (Cytoplasmic) & & & .223 & .621 \\
\hline Low & $199(45.3)$ & $190(41.3)$ & & \\
\hline High & $240(54.7)$ & $270(58.7)$ & & \\
\hline Chk1 (Nuclear) & & & .957 & .982 \\
\hline Low & $368(83.8)$ & $385(83.7)$ & & \\
\hline High & 71 (16.2) & $75(16.3)$ & & \\
\hline CHK2 & & & .190 & .673 \\
\hline Low & $63(24.8)$ & $56(20.1)$ & & \\
\hline High & $191(75.2)$ & $223(79.9)$ & & \\
\hline RECQL5 (Nuclear) & & & .767 & .964 \\
\hline Low & $159(47.7)$ & $158(46.6)$ & & \\
\hline High & $174(52.3)$ & $181(53.4)$ & & \\
\hline RECQL4 (Nuclear) & & & .763 & .991 \\
\hline Low & $174(61.5)$ & $182(60.3)$ & & \\
\hline High & $109(38.5)$ & $120(39.7)$ & & \\
\hline RECQL4 (Cytoplasmic) & & & .014 & .109 \\
\hline Low & $150(53.4)$ & $130(43.2)$ & & \\
\hline High & $131(46.6)$ & $171(56.8)$ & & \\
\hline RECQL1 (Nuclear) & & & .012 & .117 \\
\hline Low & $151(55.3)$ & $114(44.4)$ & & \\
\hline High & $122(44.7)$ & $143(55.6)$ & & \\
\hline BLM (Nuclear) & & & .002 & .026 \\
\hline Low & $111(32.4)$ & $79(21.9)$ & & \\
\hline High & $232(67.6)$ & $281(78.1)$ & & \\
\hline BLM (Cytoplasmic) & & & .373 & .606 \\
\hline Low & $249(73.2)$ & $252(70.2)$ & & \\
\hline High & $91(26.8)$ & 107 (29.8) & & \\
\hline C-MYC & & & .208 & .676 \\
\hline Low & $153(50.2)$ & $118(44.9)$ & & \\
\hline High & $152(49.8)$ & $145(55.1)$ & & \\
\hline
\end{tabular}

Bold indicates statistically significant.

Unadjusted $P$ values were calculated using the Pearson $\chi^{2}$ test. The Fisher exact test was used to obtain $P$ values where one or more of cells has an expected frequency of 5 or less. Adjusted $P$ values were calculated using the Benjamini-Hochberg false discovery rate method to adjust for multiple testing.

Abbreviations: ER = estrogen receptor; HER2 = human epidermal growth factor receptor 2; IDC-NST = invasive carcinoma of no special type; ILC = invasive lobular carcinoma; NPI = Nottingham Prognostic Index; $\mathrm{PgR}=$ progesterone receptor; $\mathrm{WRN}=$ Werner protein

aTumor size as defined by TNM Classification of Malignant Tumours (8th edition).

${ }^{\mathrm{b}}$ Grade as defined by Nottingham Grading System. 
Constantinos Savva et al

Table 3 WRN Nuclear and Cytoplasmic Protein Co-Expression in Sporadic Breast Cancer

\begin{tabular}{|c|c|c|c|c|c|c|}
\hline & \multicolumn{4}{|c|}{ WRN Nuclear and Cytoplasmic Protein Co-Expression } & \multicolumn{2}{|c|}{$P$ Value } \\
\hline & $\begin{array}{c}\text { WRNn }- \text { /WRNc - }, \\
\mathrm{N}(\%)\end{array}$ & $\begin{array}{c}\text { WRNn + } / \text { WRNc - } \\
\text { N (\%) }\end{array}$ & $\begin{array}{c}\text { WRNn - /WRNc + } \\
\mathrm{N}(\%)\end{array}$ & $\begin{array}{c}\text { WRNn + /WRNc + } \\
\mathbf{N}(\%)\end{array}$ & Unadjusted & Adjusted \\
\hline \multicolumn{7}{|l|}{ Pathologic parameters } \\
\hline Tumor size, $\mathrm{cm}^{\mathrm{a}}$ & & & & & .382 & .677 \\
\hline$\leq 1(\mathrm{~T} 1 \mathrm{a}+\mathrm{b})$ & $26(9.0)$ & $26(14.9)$ & $16(11.3)$ & $45(12.9)$ & & \\
\hline$>1-2(\mathrm{~T} 1 \mathrm{c})$ & $144(49.7)$ & $90(51.7)$ & $68(48.2)$ & $165(47.3)$ & & \\
\hline$>2-5$ (T2) & $119(41.0)$ & $56(32.2)$ & $54(38.3)$ & $134(38.4)$ & & \\
\hline$>5(\mathrm{~T} 3)$ & $1(0.3)$ & $2(1.1)$ & $3(2.1)$ & $5(1.4)$ & & \\
\hline Tumor stage & & & & & .767 & .830 \\
\hline 1 & $185(64.0)$ & $115(65.7)$ & $84(59.6)$ & $220(62.9)$ & & \\
\hline 2 & $77(26.6)$ & $43(24.6)$ & $43(30.5)$ & $104(29.7)$ & & \\
\hline 3 & $27(9.3)$ & $17(9.7)$ & $14(9.9)$ & $26(7.4)$ & & \\
\hline Tumor grade $^{b}$ & & & & & .664 & .809 \\
\hline G1 & $53(18.3)$ & $30(17.2)$ & $27(19.1)$ & 57 (16.3) & & \\
\hline G2 & $89(30.7)$ & $60(34.5)$ & $54(38.3)$ & $126(36.0)$ & & \\
\hline G3 & $148(51.0)$ & $84(48.3)$ & $60(42.6)$ & $167(47.7)$ & & \\
\hline Mitotic index & & & & & .470 & .789 \\
\hline M1 (low; mitoses < 10) & $92(33.9)$ & $66(38.6)$ & $61(43.6)$ & $130(38.1)$ & & \\
\hline M2 (medium; mitoses 10-18) & 45 (16.6) & $27(15.8)$ & $22(15.7)$ & $65(19.1)$ & & \\
\hline M3 (high; mitosis > 18) & $134(49.4)$ & $78(45.6)$ & $57(40.7)$ & $146(42.8)$ & & \\
\hline Tubule formation & & & & & .981 & 38.25 \\
\hline 1 (>75\% definite tubule) & $13(4.8)$ & $11(6.4)$ & $9(6.4)$ & $19(5.6)$ & & \\
\hline 2 (10\%-75\% definite tubule) & 89 (32.8) & $51(29.8)$ & $45(32.1)$ & $111(32.6)$ & & \\
\hline 3 ( $<10 \%$ definite tubule) & $169(62.4)$ & $109(63.7)$ & $86(61.4)$ & $211(61.9)$ & & \\
\hline Pleomorphism & & & & & .225 & .461 \\
\hline 1 (small-regular uniform) & $11(4.1)$ & $4(2.4)$ & $3(2.2)$ & $5(1.5)$ & & \\
\hline 2 (moderate variation) & 99 (36.5) & $67(39.6)$ & $65(46.8)$ & $137(40.3)$ & & \\
\hline 3 (marked variation) & $161(59.4)$ & $98(58.0)$ & $71(51.1)$ & $198(58.2)$ & & \\
\hline Tumor type & & & & & 639 & .859 \\
\hline IDC-NST & $163(56.8)$ & 98 (57.6) & $74(53.6)$ & $195(56.4)$ & & \\
\hline Tubular carcinoma & $59(20.6)$ & $33(19.4)$ & $32(23.2)$ & $76(22.0)$ & & \\
\hline Medullary carcinoma & $11(3.8)$ & $7(4.1)$ & $1(0.7)$ & $4(1.2)$ & & \\
\hline ILC & $33(11.5)$ & $22(12.9)$ & 19 (13.8) & $43(12.4)$ & & \\
\hline Others & $4(1.4)$ & $4(2.4)$ & $3(2.2)$ & $5(1.4)$ & & \\
\hline Mixed NST/lobular/special type & $17(5.9)$ & $6(3.5)$ & $9(6.5)$ & $23(6.6)$ & & \\
\hline Lymph node status & & & & & .668 & .789 \\
\hline Negative & $139(61.0)$ & $107(64.8)$ & $74(60.7)$ & $211(63.2)$ & & \\
\hline Positive (1-3) & $67(29.4)$ & $46(27.9)$ & 40 (32.8) & $104(31.1)$ & & \\
\hline Positive (>3) & $22(9.6)$ & $12(7.3)$ & $8(6.6)$ & $19(5.7)$ & & \\
\hline \multicolumn{7}{|l|}{ Aggressive phenotype } \\
\hline HER2 overexpression & & & & & .641 & .833 \\
\hline No & $244(85.6)$ & $151(87.3)$ & $125(89.9)$ & $297(88.1)$ & & \\
\hline Yes & $41(14.4)$ & $22(12.7)$ & $14(10.1)$ & $40(11.9)$ & & \\
\hline Triple negative & & & & & .599 & .898 \\
\hline No & $239(82.4)$ & $154(86.5)$ & $115(81.6)$ & $290(82.6)$ & & \\
\hline Yes & $51(17.6)$ & $24(13.5)$ & $26(18.4)$ & $61(17.4)$ & & \\
\hline NPI & & & & & .964 & 1.016 \\
\hline$\leq 3.4$ & $90(32.6)$ & $56(33.7)$ & $46(34.6)$ & 109 (32.3) & & \\
\hline$>3.4$ & $186(67.4)$ & $110(66.3)$ & 87 (65.4) & $228(67.7)$ & & \\
\hline
\end{tabular}




\section{Werner Syndrome Protein in Breast Cancer}

Table 3 Continued

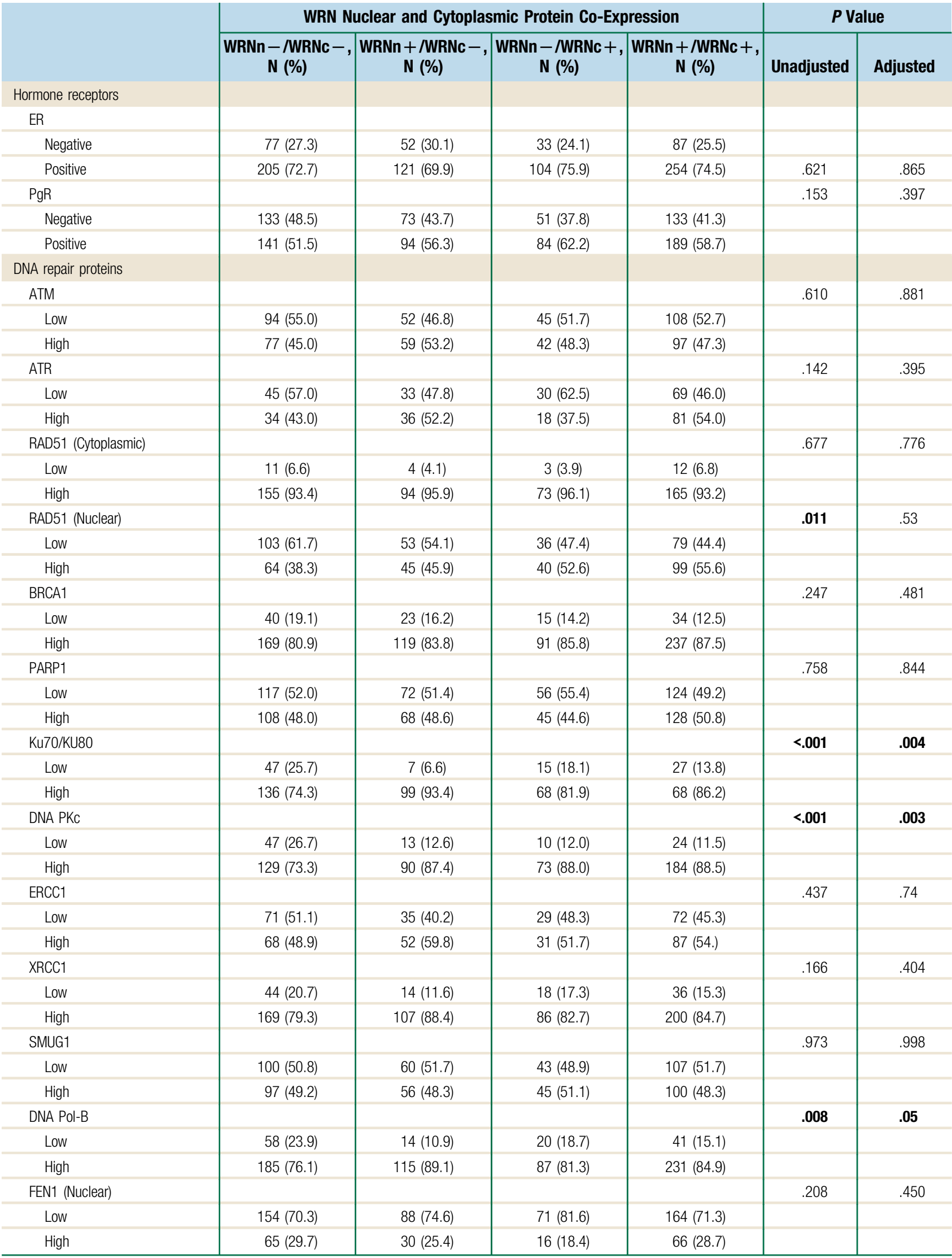


Constantinos Savva et al

Table 3 Continued

\begin{tabular}{|c|c|c|c|c|c|c|}
\hline & \multicolumn{4}{|c|}{ WRN Nuclear and Cytoplasmic Protein Co-Expression } & \multicolumn{2}{|c|}{$P$ Value } \\
\hline & $\begin{array}{c}\text { WRNn }- \text { /WRNc - } \\
\mathbf{N}(\%)\end{array}$ & $\begin{array}{c}\text { WRNn }+ \text { /WRNc - } \\
\mathrm{N}(\%)\end{array}$ & $\begin{array}{c}\text { WRNn }- \text { /WRNc }+ \text {, } \\
\mathrm{N}(\%)\end{array}$ & $\begin{array}{c}\text { WRNn }+ \text { /WRNc + } \\
\mathbf{N}(\%)\end{array}$ & Unadjusted & Adjusted \\
\hline FEN1 (Cytoplasmic) & & & & & .207 & .474 \\
\hline Low & $119(54.3)$ & $54(45.8)$ & $39(44.8)$ & $125(54.3)$ & & \\
\hline High & $100(45.7)$ & $64(54.2)$ & $48(55.2)$ & $105(45.7)$ & & \\
\hline \multicolumn{7}{|c|}{ Cell cycle and apoptosis regulators } \\
\hline p53 & & & & & .457 & .742 \\
\hline Low & $195(68.9)$ & $117(68.4)$ & $92(71.3)$ & $250(74.0)$ & & \\
\hline High & $88(31.1)$ & $54(31.6)$ & $37(28.7)$ & $88(26.0)$ & & \\
\hline CDK18 & & & & & .003 & .029 \\
\hline Low & $124(59.3)$ & $45(39.1)$ & $47(50.5)$ & $109(46.8)$ & & \\
\hline High & $85(40.7)$ & $70(60.9)$ & $46(49.5)$ & $124(53.2)$ & & \\
\hline Chk1 (Cytoplasmic) & & & & & .099 & .297 \\
\hline Low & $118(43.1)$ & $53(32.1)$ & $51(38.9)$ & $117(35.6)$ & & \\
\hline High & $156(56.9)$ & $110(67.9)$ & $80(61.1)$ & $212(64.4)$ & & \\
\hline Chk1 (Nuclear) & & & & & .643 & .808 \\
\hline Low & $233(85.0)$ & $135(81.8)$ & $113(86.3)$ & $272(82.7)$ & & \\
\hline High & $41(15.0)$ & 30 (18.2) & $18(13.7)$ & 57 (17.3) & & \\
\hline Chk2 & & & & & .078 & .253 \\
\hline Low & 39 (25.5) & $24(23.8)$ & $24(28.6)$ & $32(16.4)$ & & \\
\hline High & $114(74.5)$ & 77 (76.2) & $60(71.4)$ & $163(83.6)$ & & \\
\hline RECQL5 (Nuclear) & & & & & $<.001$ & .001 \\
\hline Low & $118(55.9)$ & $41(33.6)$ & $57(58.2)$ & $101(41.9)$ & & \\
\hline High & $93(44.1)$ & $81(66.4)$ & $41(41.8)$ & $140(58.1)$ & & \\
\hline RECQL4 (Nuclear) & & & & & .067 & .237 \\
\hline Low & $120(65.9)$ & $54(53.5)$ & $57(67.9)$ & $125(57.3)$ & & \\
\hline High & $62(34.1)$ & $47(46.5)$ & $27(32.1)$ & $93(42.7)$ & & \\
\hline RECQL4 (Cytoplasmic) & & & & & .004 & .031 \\
\hline Low & $107(59.1)$ & $43(43.0)$ & $39(46.4)$ & $91(41.9)$ & & \\
\hline High & $74(40.9)$ & $57(57.0)$ & 45 (53.6) & $126(58.1)$ & & \\
\hline RECQL1 (Nuclear) & & & & & .039 & .169 \\
\hline Low & 99 (56.6) & $52(53.1)$ & $38(50.7)$ & $76(41.8)$ & & \\
\hline High & $76(43.4)$ & $46(46.9)$ & $37(49.3)$ & $106(58.2)$ & & \\
\hline BLM (Nuclear) & & & & & .008 & .044 \\
\hline Low & 78 (34.7) & $33(28.0)$ & 22 (19.8) & $57(22.9)$ & & \\
\hline High & $147(65.3)$ & $85(72.0)$ & 89 (80.2) & $192(77.1)$ & & \\
\hline BLM (Cytoplasmic) & & & & & .05 & .195 \\
\hline Low & $174(77.7)$ & $75(64.7)$ & 81 (72.3) & 171 (69.2) & & \\
\hline High & $50(22.3)$ & $41(35.3)$ & $31(27.7)$ & $76(30.8)$ & & \\
\hline C-MYC & & & & & .372 & .690 \\
\hline Low & $105(51.5)$ & $48(47.5)$ & $35(40.2)$ & $83(47.2)$ & & \\
\hline High & $99(48.5)$ & $53(52.5)$ & $52(59.8)$ & $93(52.8)$ & & \\
\hline
\end{tabular}

Abbreviations: ER = estrogen receptor; HER2 = human epidermal growth factor receptor 2; IDC-NST = invasive carcinoma of no special type; ILC = invasive lobular carcinoma; NPI = Nottingham Prognostic Index; PgR = progesterone receptor; WRN = Werner protein.

Bold indicates statistically significant

Unadjusted $P$ values were calculated using the Pearson $\chi^{2}$ test. The Fisher exact test was used to obtain $P$ values where one or more of cells has an expected frequency of 5 or less. Adjusted $P$ values were calculated using the Benjamini-Hochberg false discovery rate method to adjust for multiple testing.

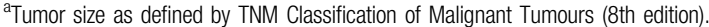

${ }^{\mathrm{b}}$ Grade as defined by Nottingham Grading System. 


\section{Werner Syndrome Protein in Breast Cancer}
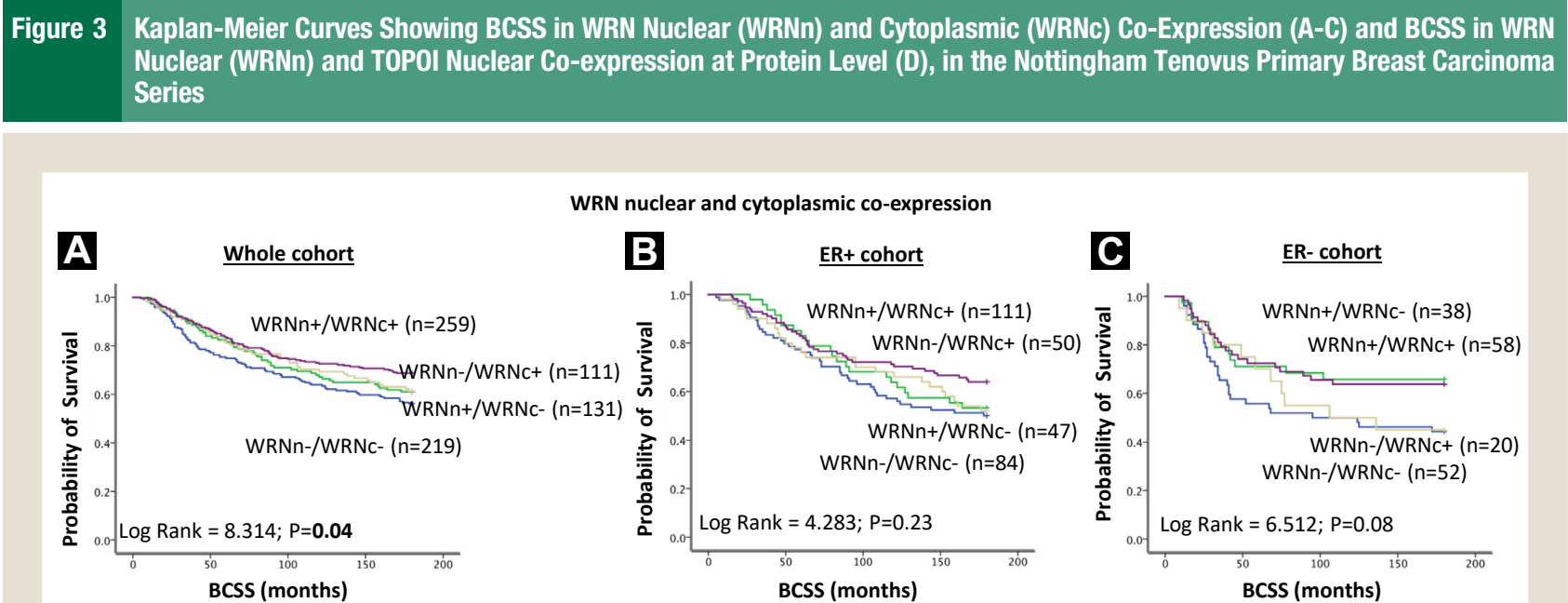

WRN nuclear and cytoplasmic co-expression
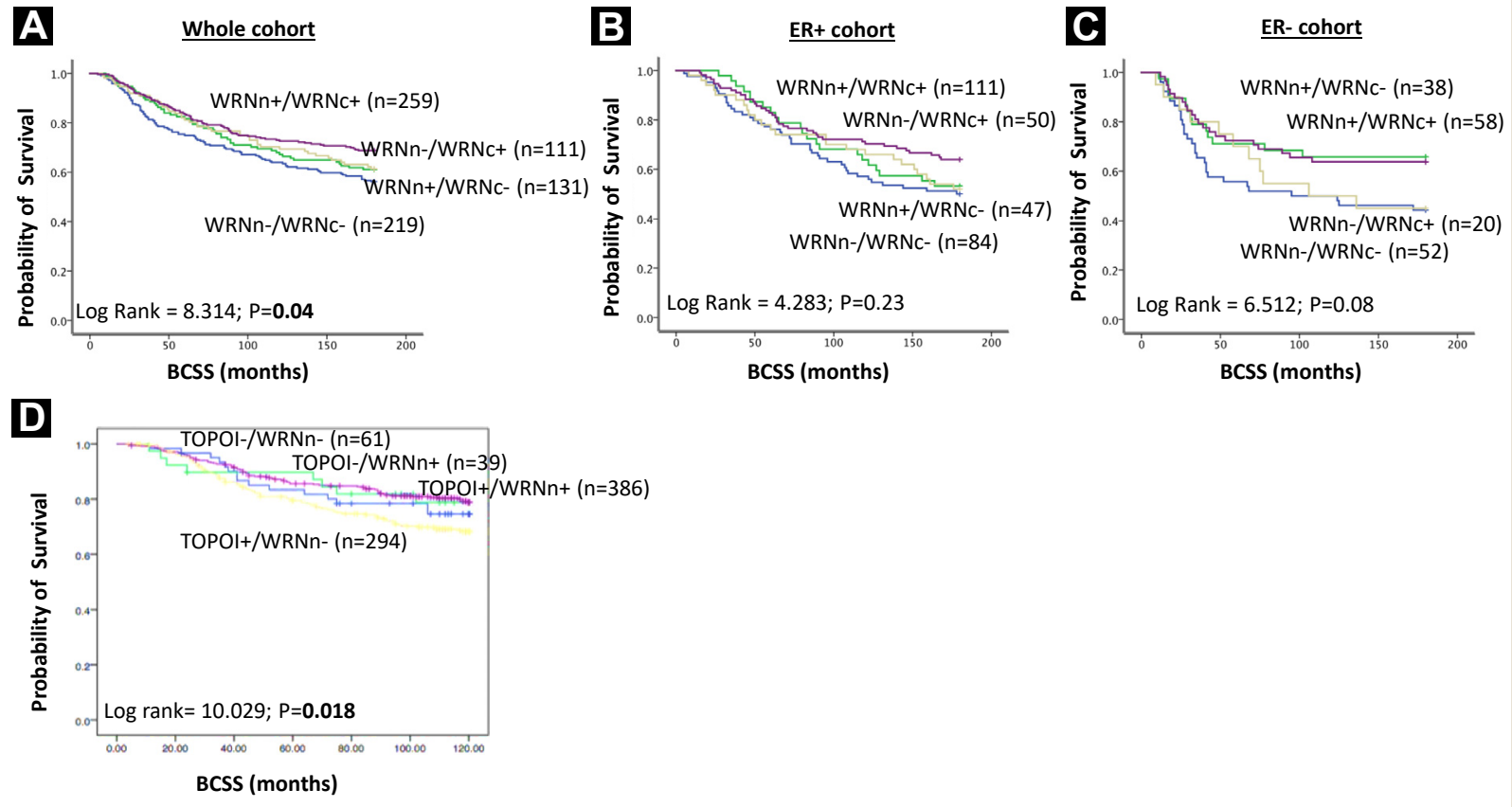

Abbreviations: BCSS $=$ breast cancer-specific survival; TOPOI $=$ topoisomerase I; WRN $=$ Werner protein .

co-expression analyses. Of these tumors, $15.4 \%$ had low nuclear/high cytoplasmic expression, $30.4 \%$ had low nuclear/low cytoplasmic expression, 36\% had high nuclear/high cytoplasmic expression, and $18.2 \%$ demonstrated high nuclear/low cytoplasmic expression.
When we combined the nuclear and cytoplasmic expression of WRN protein, low cytoplasmic and nuclear co-expression of WRN protein was statistically associated with an aggressive molecular phenotype. Specifically, there was strong evidence of association

\section{Figure 4 Kaplan-Meier Curves Showing BCSS in WRN Nuclear (WRNn) and Cytoplasmic (WRNc) Expression at Protein Level in the BRCA-Mutated Cohort}
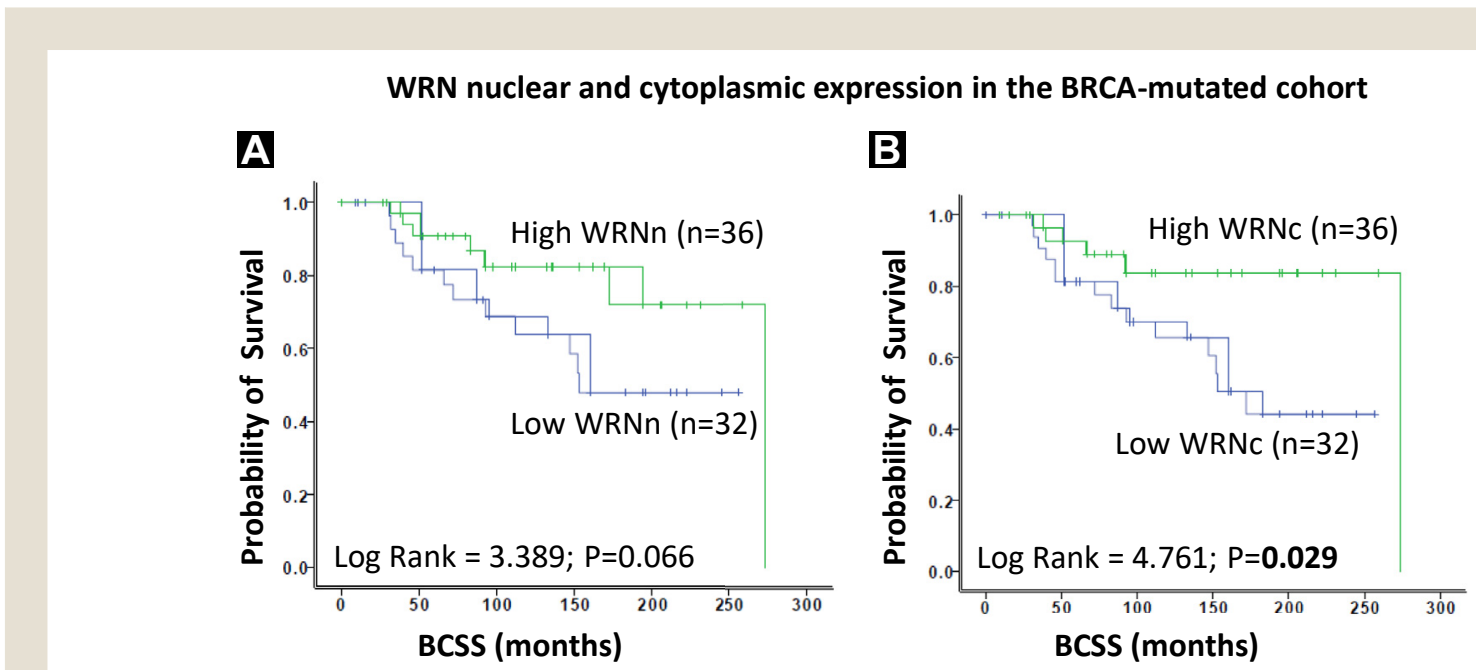

Abbreviations: BCSS $=$ breast cancer-specific survival; WRN $=$ Werner protein. 
Table 4 Cox Proportional Hazard Multivariate Analysis of WRN Protein Expression in Sporadic Breast Cancer

\begin{tabular}{l|c|c|c|c} 
Breast cancer-specific & & & \multicolumn{2}{|c}{$95 \%$ CI of Exp (B) } \\
survival & $\boldsymbol{P}$ Value & Exp (B) & Lower & Upper \\
\cline { 2 - 4 } Stage & $\mathbf{< . 0 0 1}$ & 1.954 & 1.442 & 2.649 \\
Grade & $\mathbf{< . 0 0 1}$ & 2.473 & 1.636 & 3.738 \\
HER2 overexpression & .242 & 1.313 & 0.832 & 2.073 \\
NPI & .531 & 0.793 & 0.383 & 1.639 \\
WRN (Cytoplasmic) & $\mathbf{. 0 3 9}$ & 0.677 & 0.467 & 0.980 \\
WRN (Nuclear) & $\mathbf{. 0 3 2}$ & 0.672 & 0.466 & 0.967 \\
\hline TOPO I (Nuclear) & .270 & 1.234 & 0.849 & 1.794 \\
\hline
\end{tabular}

Abbreviations: $\mathrm{Cl}=$ confidence interval; HER2 = human epidermal growth factor receptor 2; NPI = Nottingham Prognostic Index; TOPO I = topoisomerase I; WRN = Werner protein Bold indicates statistically significant.

between low WRN nuclear and cytoplasmic co-expression and low levels of KU70/KU80 $(P=.004)$, DNA-PK $(P=.003)$, DNA Pol-B $(P=.05)$, CKD18 $(P=.029)$, cytoplasmic RECQL4 $(P=.031)$, and nuclear BLM protein expression $(P=.044)$ (Table 3$)$.

These results suggest that low WRN protein expression is associated with low levels of DNA repair and cell cycle regulation in patients with breast cancer.

\section{Low WRNProtein Expression is Associated With Worse BCSS}

In univariate analysis, patients whose tumor had low WRN nuclear expression had significantly $(P=.02)$ worse overall BCSS in the Nottingham Tenovus Primary Breast Carcinoma series (Figure 2A). Furthermore, a statistically significant worse BCSS was observed in the ER-negative cohort $(P=.012)$ (Figure 2C). Tumors with low WRN cytoplasmic expression also demonstrated poor BCSS, which was statistically significant $(P=.017)$. We then evaluated the impact of WRN nuclear and cytoplasmic co-expression on BCSS. In the whole cohort, patients with low nuclear/low cytoplasmic WRN expression had poor BCSS $(P=.04)$, suggesting that low expression has prognostic significance (Figure $3 \mathrm{~A}$ ). The impact of WRN protein expression was also evaluated in the BRCA-mutated cohort, where low WRN cytoplasmic expression conferred the shortest BCSS $(P=.029)$ (Figure 4B). Although low WRN nuclear expression showed a trend towards worse BCSS, this was not statistically significant $(P=.066)$ (Figure $4 \mathrm{~A})$.

\section{Low WRN and High TOPOI Co-expression is Associated With Poor BCSS}

As discussed previously, WRN interacts with TOPOI and enhances the ability of TOPOI to relax the supercoiled DNA. In WRN nuclear and TOPOI nuclear co-expression analysis, tumors with low WRN nuclear expression and high TOPOI expression had poor BCSS in the whole cohort (Figure 3D).

\section{WRN Nuclear and Cytoplasmic Expression are Independent Predictors of BCSS}

In multivariate analysis, WRN nuclear and cytoplasmic expression were independent prognostic factors for BCSS $(P=.039$ and $P=.032$, respectively). Tumor stage and grade were also independently associated with BCSS (Table 4).

\section{Discussion}

WRN is the largest family member of the human RECQ helicase protein. WRN is the only DNA RECQ helicase that contains a nuclease domain and catalyzes DNA-dependent reactions. WRN acts on various DNA structures to help with DNA repair through its enzymatic functions. Although WS cells demonstrate compromised survival after exposure to replication stress, certain cells with chromosomal abnormalities enter cell replication that increases the degree of mutations and, consequently, the level of genomic instability in survival cells, leading to malignant transformation. ${ }^{12}$

Germline mutations in WRN lead to defects in DNA repair, premature aging, and cancer susceptibility. ${ }^{22-24}$ Genetic epidemiologic studies identified certain polymorphisms of the WRN gene that are associated with increased risk of breast cancer. ${ }^{25-27}$ Specifically, the CC genotype of WRN rs1346044 has been associated with a 2 -fold risk of developing breast cancer. ${ }^{27}$ In addition, a meta-analysis evaluated 7 epidemiologic studies and demonstrated that the CC genotype of Cys1367Arg polymorphism was also associated with a 1.43-times increased risk of breast cancer. ${ }^{25} \mathrm{~A}$ case-control study in Chinese women that included approximately 4000 patients also showed that the variant genotype of WRN Leu1074Phe was associated with a 1.36-times higher risk of breast cancer. $^{26}$

We have previously shown, at a transcriptomic level, that low WRN mRNA expression was associated with aggressive clinicopathologic features such as high grade, lymph node stage, and human epidermal growth factor receptor 2 (HER2) overexpression and distinct aggressive molecular phenotypes as described by Curtis et $\mathrm{al}^{28}$ including PAM50.Her2, PAM50.LumB, Genufu subtype (ER ${ }^{+} / \mathrm{HER}^{-} /$high proliferation), and Genufu subtype $\left(\mathrm{HER}_{2}{ }^{+}\right)$breast tumors. ${ }^{29}$ Low WRN mRNA level was also associated with poor BCSS. ${ }^{29}$ At the protein level, we observed complex staining patterns, with tumors showing negative, nuclear, and/or cytoplasmic WRN staining. Similar to the WRN mRNA expression data, ${ }^{29}$ low cytoplasmic and low nuclear WRN protein levels were associated with poor BCSS. However, low WRN protein expression was not significantly linked to clinicopathologic characteristics. The mechanism of regulation of WRN expression is not clearly understood. It has been previously shown that epigenetic inactivation of WRN is common in solid tumors, with the highest frequency in colorectal cancer $(37.9 \% ; 69 / 182)$ and a 


\section{Werner Syndrome Protein in Breast Cancer}

prevalence of $17.2 \%$ (10/58) in breast tumors. ${ }^{30}$ Nevertheless, the authors did not describe any clinicopathologic associations in this study. In our previous study, ${ }^{29}$ we have found that WRN mRNA expression level was low in 326 (16.5\%) of 1977 breast tumors, which is in accordance with the findings of the study from Agrelo et al. ${ }^{30}$

Wild type WRN protein contains a nuclear localization signal motif in the region of C-terminus. ${ }^{31}$ This $\mathrm{C}$-terminal sequence, which is often lost as a result of mutations, is necessary for nuclear localization of the WRN protein. ${ }^{31}$ Most of the mutations of the WS gene, which are found in its coding region, lead to instability of WRN mRNA and truncation of the protein with loss of the nuclear localization signal. ${ }^{32}$ Impaired nuclear import probably constitutes an important contributing factor in the development of WS. ${ }^{31} \mathrm{Fur}-$ thermore, the transcriptional status of the cells determines the localization of WRN protein. ${ }^{33}$ WRN protein is accumulated in the nucleoli when rRNA transcription is stimulated, whereas the lack of transcriptional activity when cells enter $\mathrm{G} 0$ or during late $\mathrm{G} 2$ phase of the cell cycle leads to the release of WRN protein from the nucleoli to nucleoplasm. ${ }^{33}$ During the metaphase, WRN protein is released from the condensed chromatic to the cytoplasm. ${ }^{34}$ Moreover, WRN CpG island promoter hypermethylation undergoes hypermethylation in human cancer cells, leading to loss of WRN protein expression and hypersensitivity to topoisomerase inhibitors and DNA-damaging agents. ${ }^{30}$ These findings suggest that mutations or epigenetic silencing may explain the different localization of WRN protein, which plays a key role in DNA damage response.

Our findings indicate that low WRN expression in human tumors may lead to a 'mutator phenotype' expressed as aggressive breast cancers. Inactivation of WRN protein makes tumor cells susceptible to TOPO I poison and DNA-damaging agents. Cellular senescence is increased in WRN-deficient cells, in the presence of constant DNA damage and after treatment with chemotherapeutic agents such as camptothecin. ${ }^{35-37}$ In colorectal tumors, hypermethylation of WRN promoter $\mathrm{CpG}$ island was correlated with good response and better overall survival after treatment with irinotecan. ${ }^{30}$ Specifically, WRN knockdown and camptothecin treatment both induce DNA damage and cause increased p21 expression and SA- $\beta$-gal activity in colon cancer. ${ }^{35}$ On the other hand, the rescue of WRN in tumor cells treated with camptothecin enhanced the efficiency of DNA damage response to eliminate cytotoxic DNA lesions. ${ }^{29}$

There is evidence to suggest that RECQ helicases cooperate with each other to perform their vital biological roles so there may be functional redundancy between them. ${ }^{38-41}$ Hence, we looked at correlation between WRN and RECQL1, RECQL4, RECQL5, and BLM helicases that showed a significant correlation between low nuclear RECQL4 and high nuclear WRN $(P<.05)$. Further analysis among the 5 helicases demonstrated a significant correlation between low RECQL1 nuclear and high nuclear BLM $(P<.05)$; low nuclear RECQL4 and high nuclear BLM $(P<.05)$, and low nuclear RECQL5 and high nuclear BLM $(P<.05)$ (see Supplemental Table 5 in the online version). These findings suggest that there is a possibility that low expression of one helicase in breast cancer might lead to compensatory increase in the expression of another helicase.

In view of the interaction between WRN and TOPO I, we carried out combined WRN and TOPO I analysis and showed that low WRN nuclear expression in TOPO I-overexpressed tumors is associated with worse BCSS. This is consistent with our previously published data at the mRNA level, where we demonstrated that low WRN expression in TOPO I-high tumors is associated with poor BCSS in the whole cohort. ${ }^{29}$ TOPO I plays a vital role during replication and proliferation. As WRN is involved in various DNA repair pathways, it is possible that it promotes the DNA repair ability of established tumor cells to withstand DNA damage induced by endogenous and exogenous agents. A recent study identified NSC 19630 as a specific inhibitor of WRN, which synergistically inhibited cell proliferation and induced DNA damage with topotecan. ${ }^{42}$

Targeting DNA helicases for therapeutic purposes has gained interest with the development of other DNA repair inhibitors, such as poly (ADP) ribosylase (PARP) inhibitors used in synthetic lethality approaches to control carcinogenesis in homologous recombinationdefective BRCA1/2-deficient tumors. A recent study that performed genome-scale CRISPR-Cas9 screen in 324 human cancer cell lines from 30 tumor types identified WRN as a potential synthetic lethality target for cancers with microsatellite instability. ${ }^{43}$ Hence, we evaluated the prognostic impact of WRN expression in BRCA-mutated tumors that showed that low WRN expression is associated with worse BCSS. WRN and BRCA1 facilitate DNA damage response in a coordinated manner, as BRCA1 binds directly to WRN by stimulating its exonuclease and helicase activity. ${ }^{44}$ This interaction is enhanced in HeLa cells exposed to DNA cross-linking agents, where WRN participates in the DNA repair via its helicase activity. ${ }^{44}$ PARP1 inhibits both WRN exonuclease and helicase activities, an interaction that is influenced by the poly (ADP-ribosyl)ation status of PARP1. ${ }^{45}$ WS cells are deficient in the poly (ADP-ribosyl)ation pathway after they are treated with agents that induce oxidative stress and DNA alkylation. ${ }^{46}$ Further understanding of the functional interaction between WRN and PARP1 in BRCA-mutated tumors may lead to novel therapeutic approaches. Given the role of RECQ helicases in homologous recombination, it will be important to study the possibility that RECQ helicases could have a synthetic lethality relation with PARP inhibitors or other DNA repair inhibitors such as ATM/ WEE1, which are currently under wide investigation in clinical trials.

In conclusion, we provide evidence that WRN protein expression can influence molecular phenotype and clinical outcomes in patients with breast cancer. We have also shown the prognostic significance of low WRN expression in TOPO I-overexpressed tumors as these patients might benefit from TOPO I poisons.

\section{Clinical Practice Points}

- WRN protein is a DNA helicase involved in genomic stability and commonly inactivated in breast tumors.

- We showed that low WRN protein expression is associated with worse survival and aggressive molecular phenotype in patients with sporadic breast cancer.

- WRN expression in TOPO I-overexpressed tumors is also associated with poor survival, indicating that these patients might benefit from TOPO I poisons.

- Low WRN expression is associated with worse BCSS in BRCAmutated breast tumors. Further understanding of the functional interaction between WRN and PARP1 in BRCA-mutated tumors may lead to novel therapeutic approaches.

- These findings can be used to optimize the risk stratification for personalized treatment. 


\section{Acknowledgments}

The authors thank the Nottingham Health Science Biobank and Breast Cancer Now Tissue Bank for the provision of tissue samples.

\section{Disclosure}

The authors have stated that they have no conflicts of interest.

\section{Ethical Approval}

Ethical approval was obtained from the Nottingham Research Ethics Committee (Reference number C202313). All procedures performed in studies involving human participants were in accordance with the ethical standards of the institutional and/or national research committee and with the 1964 Helsinki declaration and its later amendments or comparable ethical standards.

\section{Informed Consent}

All data were anonymized, and all personal identifiers were removed.

\section{Supplemental Data}

Supplemental tables and figures accompanying this article can be found in the online version at https://doi.org/10.1016/j.clbc.2020. 07.013

\section{References}

1. Bohr VA. Rising from the RecQ-age: the role of human RecQ helicases in genome maintenance. Trends Biochem Sci 2008; 33:609-20.

2. Croteau DL, Popuri V, Opresko PL, Bohr VA. Human RecQ helicases in DNA repair, recombination, and replication. Annu Rev Biochem 2014; 83:519-52.

3. Goto M, Rubenstein M, Weber J, Woods K, Drayna D. Genetic linkage of Werner's syndrome to five markers on chromosome 8. Nature 1992; 355:735-8.

4. Schellenberg GD, Martin GM, Wijsman EM, Nakura J, Miki T, Ogihara T. Homozygosity mapping and Werner's syndrome. Lancet 1992; 339:1002.

5. Harrigan JA, Wilson DM 3rd, Prasad R, et al. The Werner syndrome protein operates in base excision repair and cooperates with DNA polymerase beta. Nucleic Acids Res 2006; 34:745-54.

6. Thompson LH, Schild D. Recombinational DNA repair and human disease. Mutat Res 2002; 509:49-78.

7. Laine JP, Opresko PL, Indig FE, Jarrigan JA, von Kobbe C, Bohr VA. Werner protein stimulates topoisomerase I DNA relaxation activity. Cancer Res 2003; 63: 7136-46.

8. Lauper JM, Krause A, Vaughan TL, Monnat RJ Jr. Spectrum and risk of neoplasia in Werner syndrome: a systematic review. PLoS One 2013; 8:e59709.

9. Shen JC, Loeb LA. The Werner syndrome gene: the molecular basis of RecQ helicase-deficiency diseases. Trends Genet 2000; 16:213-20.

10. van Brabant AJ, Stan R, Ellis NA. DNA helicases, genomic instability, and human genetic disease. Annu Rev Genomics Hum Genet 2000; 1:409-59.

11. Yu CE, Oshima J, Wijsman EM, et al. Mutations in the consensus helicase domains of the Werner syndrome gene. Werner's Syndrome Collaborative Group. Am J Hum Genet 1997; 60:330-41.

12. Mukherjee S, Sinha D, Bhattacharya S, Srinivasan K, Abdisalaam S, Asaithamby A. Werner syndrome protein and DNA replication. Int I Mol Sci 2018; 19:3442.

13. Opresko PL, Calvo JP, von Kobbe C. Role for the Werner syndrome protein in the promotion of tumor cell growth. Mech Ageing Dev 2007; 128:423-36.

14. Sharma S, Doherty KM, Brosh RM Jr. Mechanisms of RecQ helicases in pathways of DNA metabolism and maintenance of genomic stability. Biochem J2006; 398:319-37.

15. Szekely AM, Bleichert F, Nümann A, et al. Werner protein protects nonproliferating cells from oxidative DNA damage. Mol Cell Biol 2005; 25:10492-506.

16. Otterlei M, Bruheim P, Ahn B, et al. Werner syndrome protein participates in a complex with RAD51, RAD54, RAD54B and ATR in response to ICL-induced replication arrest. J Cell Sci 2006; 119:5137.

17. Arora A, Abdel-Fatah TMA, Agarwal D, et al. Clinicopathological and prognostic significance of RECQL5 helicase expression in breast cancers. Carcinogenesis 2016; 37:63-71.

18. Arora A, Agarwal D, Abdel-Fatah TM, et al. RECQL4 helicase has oncogenic potential in sporadic breast cancers. J Pathol 2016; 238:495-501.
19. Savva C, De Souza K, Ali R, Rakha EA, Green AR, Madhusudan S. Clinicopathological significance of ataxia telangiectasia-mutated (ATM) kinase and ataxia telangiectasia-mutated and Rad3-related (ATR) kinase in MYC overexpressed breast cancers. Breast Cancer Res Treat 2019; 175:105-15.

20. McShane LM, Altman DG, Sauerbrei W, Taube SE, Gion M, Clark GM. Statistics Subcommittee of the NCI-EORTC Working Group on Cancer Diagnostics. Reporting recommendations for tumor marker prognostic studies (REMARK). J Natl Cancer Inst 2005; 97:1180-4.

21. Benjamini $Y$, Hochberg $Y$. Controlling the false discovery rate: a practical and powerful approach to multiple testing. J R Stat Soc Ser B (Methodological) 1995; 57:289-300.

22. Chun SG, Yee NS. Werner syndrome as a hereditary risk factor for exocrine pancreatic cancer: potential role of WRN in pancreatic tumorigenesis and patienttailored therapy. Cancer Biol Ther 2010; 10:430-7.

23. Ding SL, Yu JC, Chen ST, Hsu GC, Shen CY. Genetic variation in the premature aging gene WRN: a case-control study on breast cancer susceptibility. Cancer Epidemiol Biomarkers Prev 2007; 16:263-9.

24. Chun SG, Shaeffer DS, Bryant-Greenwood PK. The Werner's syndrome RecQ helicase/exonuclease at the nexus of cancer and aging. Hawaii Med J 2011; 70:52-5.

25. Wang B, Li G, Sun F, Dong N, Sun Z, Jiang D. Association between WRN Cys1367Arg $(\mathrm{T}>\mathrm{C})$ and cancer risk: a meta-analysis. Technol Cancer Res Treat 2014; 15:20-7.

26. Wang Z, Xu Y, Tang J, et al. A polymorphism in Werner syndrome gene is associated with breast cancer susceptibility in Chinese women. Breast Cancer Res Treat 2009; 118:169-75.

27. Zins K, Frech B, Taubenschuss E, Schneeberger C, Abraham D, Schreiber M. Association of the rs1346044 polymorphism of the Werner syndrome gene RECQL2 with increased risk and premature onset of breast cancer. Int J Mol Sci 2015; 16:29643-53.

28. Curtis C, Shah SP, Chin SF, et al. The genomic and transcriptomic architecture of 2,000 breast tumours reveals novel subgroups. Nature 2012; 486:346-52.

29. Shamanna RA, Lu H, Croteau DL, et al. Camptothecin targets WRN protein: mechanism and relevance in clinical breast cancer. Oncotarget 2016; 7:13269-84.

30. Agrelo R, Cheng WH, Setien F, et al. Epigenetic inactivation of the premature aging Werner syndrome gene in human cancer. Proc Natl Acad Sci US A 2006; 103:8822-7.

31. Matsumoto T, Shimamoto A, Goto M, Furuichi Y. Impaired nuclear localization of defective DNA helicases in Werner's syndrome. Nat Genet 1997; 16:335-6.

32. Smith JA, Ndoye AMN, Geary K, Lisanti MP, Igoucheva O, Daniel R. A role for the Werner syndrome protein in epigenetic inactivation of the pluripotency factor Oct4. Aging Cell 2010; 9:580-91.

33. Suzuki T, Shiratori M, Furuichi Y, Matsumoto T. Diverged nuclear localization of Werner helicase in human and mouse cells. Oncogene 2001; 20:2551-8.

34. Shiratori M, Sakamoto S, Suzuki N, et al. Detection by epitope-defined monoclonal antibodies of Werner DNA helicases in the nucleoplasm and their upregulation by cell transformation and immortalization. J Cell Biol 1999; 144:1-9.

35. Han Z, Wei W, Dunaway S, et al. Role of p 21 in apoptosis and senescence of human colon cancer cells treated with camptothecin. J Biol Chem 2002; 277:17154-60.

36. Lu H, Fang EF, Sykora P, et al. Senescence induced by RECQL4 dysfunction contributes to Rothmund-Thomson syndrome features in mice. Cell Death Dis 2014; 5:e1226.

37. Rodier F, Coppé JP, Patil CK, et al. Persistent DNA damage signalling triggers senescence-associated inflammatory cytokine secretion. Nat Cell Biol 2009; 11: 973-9.

38. Popuri V, Huang J, Ramamoorthy M, Tadokoro T, Croteau DL, Bohr VA. RECQL5 plays co-operative and complementary roles with WRN syndrome helicase. Nucleic Acids Res 2017; 45:1566.

39. Hu Y, Lu X, Barnes E, Yan M, Lou H, Luo G. Recal5 and Blm RecQ DNA helicases have nonredundant roles in suppressing crossovers. Mol Cell Biol 2005; 25:3431-42.

40. Otsuki M, Seki M, Inoue E, et al. Analyses of functional interaction between RECQL1, RECQL5, and BLM which physically interact with DNA topoisomerase IIIalpha. Biochim Biophys Acta 2008; 1782:75-81.

41. Singh DK, Popuri V, Kulikowicz T, et al. The human RecQ helicases BLM and RECQL4 cooperate to preserve genome stability. Nucleic Acids Res 2012; 40: 6632-48.

42. Aggarwal M, Sommers JA, Shoemaker RH, Brosh RM Jr. Inhibition of helicase activity by a small molecule impairs Werner syndrome helicase (WRN) function in the cellular response to DNA damage or replication stress. Proc Natl Acad Sci U S A 2011; 108:1525-30.

43. Behan FM, Iorio F, Picco G, et al. Prioritization of cancer therapeutic targets using CRISPR-Cas9 screens. Nature 2019; 568:511-6.

44. Cheng WH, Kusumoto R, Opresko PL, et al. Collaboration of Werner syndrome protein and BRCA1 in cellular responses to DNA interstrand cross-links. Nucleic Acids Res 2006; 34:2751-60.

45. von Kobbe C, Harrigan JA, Schreiber V, et al. Poly(ADP-ribose) polymerase 1 regulates both the exonuclease and helicase activities of the Werner syndrome protein. Nucleic Acids Res 2004; 32:4003-14.

46. von Kobbe C, Harrigan JA, May A, et al. Central role for the Werner syndrome protein/poly(ADP-ribose) polymerase 1 complex in the poly(ADP-ribosyl)ation pathway after DNA damage. Mol Cell Biol 2003; 23:8601-13. 


\section{Werner Syndrome Protein in Breast Cancer}

\section{Supplemental Data}

\section{Supplemental Figure 1 Kaplan-Meier Curves Showing BCSS in WRNn at protein Level Nottingham Tenovus Primary Breast Cancer Series}

\section{WRN protein nuclear expression}

\section{ER- cohort; NPI>3.4; had chemotherapy}

\section{A}

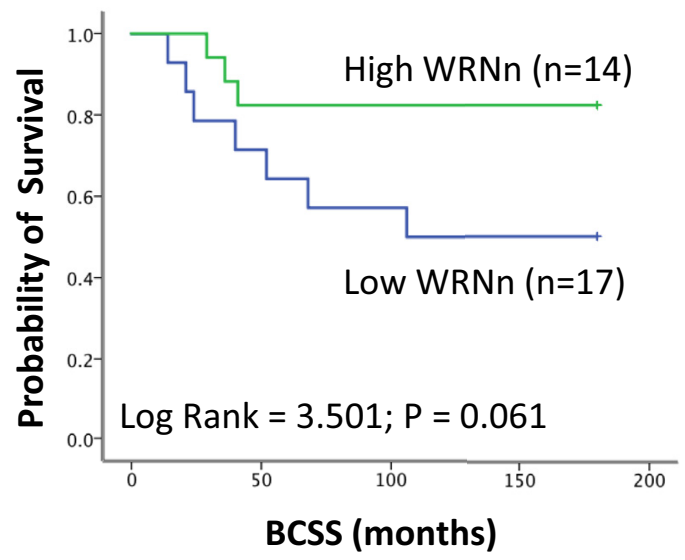

\section{ER- cohort; NPI>3.4; no chemotherapy}

\section{$\mathbf{B}$}

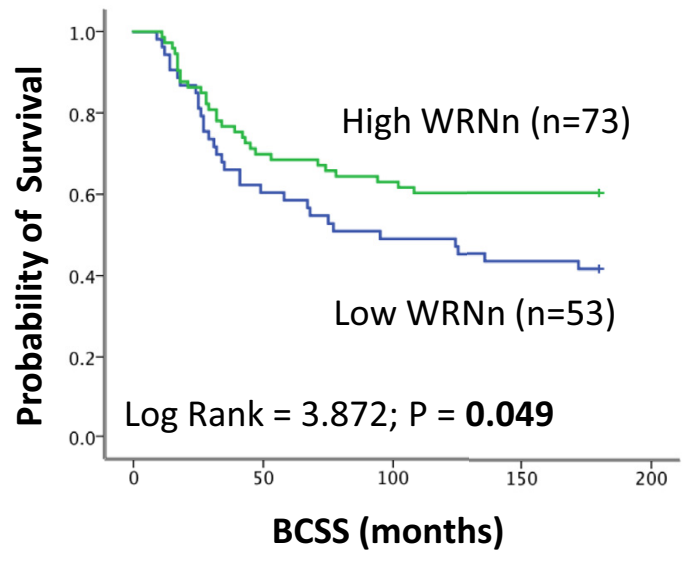

Abbreviations: BCSS $=$ breast cancer-specific survival; $\mathrm{ER}^{-}=$estrogen receptor-negative; NPI $=$Nottingham Prognostic Index; WRN $=$Werner protein; WRNn $=$WRN nuclear expression. 
Supplemental Table 1 Clinicopathologic Characteristics of Nottingham Tenovus Primary Breast Cancer Series

\begin{tabular}{|c|c|c|c|}
\hline Variable & $\mathbf{n}^{\mathrm{a}}$ & Cases & $\%$ \\
\hline Menopausal status & 1650 & & \\
\hline Pre-menopausal & & 612 & 37.0 \\
\hline Postmenopausal & & 1038 & 63.0 \\
\hline Tumor grade $(\mathrm{NGS})^{b}$ & 1650 & & \\
\hline G1 & & 306 & 18.5 \\
\hline G2 & & 531 & 32.2 \\
\hline G3 & & 813 & 49.3 \\
\hline Lymph node stage & 1650 & & \\
\hline Negative & & 1056 & 64.0 \\
\hline Positive (1-3 nodes) & & 486 & 29.5 \\
\hline Positive (> 3 nodes) & & 108 & 6.5 \\
\hline Tumor size, $\mathrm{cm}^{\mathrm{C}}$ & 1650 & & \\
\hline $\mathrm{T} 1 \mathrm{a}+\mathrm{b}(\leq 1.0)$ & & 187 & 11.0 \\
\hline $\mathrm{T} 1 \mathrm{c}(>1.0-2.0)$ & & 868 & 53.0 \\
\hline T2 (> 2.0-5) & & 579 & 35.0 \\
\hline $\mathrm{T} 3(>5)$ & & 16 & 1.0 \\
\hline Tumor type & 1650 & & \\
\hline IDC-NST & & 941 & 57 \\
\hline Tubular & & 349 & 21 \\
\hline ILC & & 160 & 10 \\
\hline Medullary (typical/atypical) & & 41 & 2.5 \\
\hline Others & & 159 & 9.5 \\
\hline NPI subgroups & 1650 & & \\
\hline Excellent PG (2.08-2.40) & Low risk & 207 & 12.5 \\
\hline Good PG (2.42-3.40) & & 331 & 20.1 \\
\hline Moderate I PG (3.42 to 4.4) & High risk & 488 & 29.6 \\
\hline Moderate II PG (4.42 to 5.4 ) & & 395 & 23.9 \\
\hline Poor PG (5.42 to 6.4) & & 170 & 10.3 \\
\hline Very poor PG (6.5 to 6.8 ) & & 59 & 3.6 \\
\hline Survival at 20 years & 1650 & & \\
\hline Alive and well & & 1055 & 64.0 \\
\hline Dead from disease & & 468 & 28.4 \\
\hline Dead from other causes & & 127 & 7.6 \\
\hline \multicolumn{4}{|l|}{ Adjuvant systemic therapy } \\
\hline No adjuvant systemic therapy & & 665 & 42.0 \\
\hline Hormone therapy & & 642 & 41.0 \\
\hline Chemotherapy & & 307 & 20.0 \\
\hline Hormone + chemotherapy & & 46 & 3.0 \\
\hline
\end{tabular}

Abbreviations: IDC-NST = invasive carcinoma of no special type; ILC = invasive lobular carcinoma; NPI = Nottingham Prognostic Index; PG = prognostic group

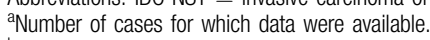

${ }^{\mathrm{b}}$ Grade as defined by Nottingham Grading System.

${ }^{C}$ Tumor size as defined by TNM Classification of Malignant Tumours (8th edition). 


\section{Werner Syndrome Protein in Breast Cancer}

\section{Supplemental Table 2 Clinicopathologic Characteristics of the BRCA-Mutated Cohort}

\section{Variable}

Mean age at diagnosis, y (range)

Tumor size, $\mathrm{cm}$

$<2$

$\geq 2$

Tumor type

Ductal/NST

Lobular/mixed

Medullary (typical/atypical)

Other

Tumor grade (NGS)

$$
1
$$

2

3

Stage

1

2

3

Vascular invasion

No

Yes

NPI subgroups

Good PG

Moderate PG

Poor PG

Estrogen receptor (ER)

Negative

Positive

HER2

Negative

Positive

Triple negative

No

Yes

Recurrence

No

Yes

Mean survival, mos (range)

Alive

Dead

Bilateral cancer

No

Yes
BRCA1-Mutated Cancer ( $\mathrm{n}=48$ ),

N (\%)

$40.66(26-64)$

$24(50.0)$

$24(50.0)$

39 (81.2)

1 (2.1)

7 (14.6)

$1(2.1)$

$1(2.1)$

$4(8.3)$

$43(89.6)$

30 (65.2)

15 (32.6)

1 (2.2)

$29(63.0)$

$17(37.0)$

$3(6.5)$

34 (73.9)

9 (19.6)

39 (83.0)

$8(17.0)$

45 (95.7)

2 (4.3)

15 (32.6)

$31(67.4)$

41 (85.4)

7 (15.9)

$121.5(9-265)$

$33(75.0)$

11 (25.0)

$33(75.0)$

$11(25.0)$
BRCA2-Mutated Cancer (n = 27),

N (\%)

$45(28-71)$

11 (40.7)

16 (59.3)

$18(66.7)$

$7(25.9)$

$2(7.4)$

0

0

7 (24.0)

$20(74.1)$

17 (63.0)

8 (29.6)

$2(7.4)$

$20(74.1)$

7 (25.9)

6 (22.2)

15 (55.6)

6 (22.2)

4 (14.8)

23 (85.2)

26 (96.3)

1 (3.7)

25 (92.6)

$2(7.4)$

$22(81.5)$

5 (20.8)

$87.3(13-206)$

16 (66.7)

8 (33.3)

$20(83.3)$

4 (16.7)

Abbreviations: $\mathrm{NPI}=$ Nottingham Prognostic Index; $P G=$ prognostic group

${ }^{a} A$ total of 75 tumor samples from 68 patients with confirmed germline mutations for BRCA1 or BRCA2.

${ }^{b}$ Grade as defined by Nottingham Grading System. 
Constantinos Savva et al

Supplemental Table 3 Werner Nuclear Protein Expression in BRCA-mutated Breast Tumors

\begin{tabular}{|c|c|c|c|c|}
\hline & \multicolumn{2}{|c|}{ Werner Nuclear Protein Expression } & \multicolumn{2}{|c|}{$P$ Value } \\
\hline & Low, N (\%) & High, N (\%) & Unadjusted & Adjusted \\
\hline Tumor size, $\mathrm{cm}^{\mathrm{a}}$ & & & .467 & 1.87 \\
\hline$<1(\mathrm{~T} 1 \mathrm{a}+\mathrm{b})$ & $4(13.3)$ & $1(2.9)$ & & \\
\hline$>1-2(\mathrm{~T} 1 \mathrm{c})$ & $11(36.7)$ & $14(41.2)$ & & \\
\hline$>2-5$ (Т2) & $14(46.7)$ & $17(5.0)$ & & \\
\hline$>5$ (T3) & $1(3.3)$ & $2(5.9)$ & & \\
\hline Tumor stage & & & .227 & 1.59 \\
\hline 1 & $21(65.6)$ & $20(58.8)$ & & \\
\hline 2 & $11(34.4)$ & $11(32.4)$ & & \\
\hline 3 & 0 & $3(8.8)$ & & \\
\hline \multicolumn{5}{|l|}{ Tumor grade ${ }^{b}$} \\
\hline G2 & $4(12.5)$ & $5(13.9)$ & & \\
\hline G3 & $28(87.5)$ & $31(86.1)$ & .866 & .866 \\
\hline Vascular invasion & & & .319 & 1.60 \\
\hline No & $18(58.1)$ & $23(6.5)$ & & \\
\hline Probable & 0 & $2(5.3)$ & & \\
\hline Yes & $13(41.9)$ & $10(26.3)$ & & \\
\hline Tumor type & & & .161 & 1.45 \\
\hline IDC-NST & 28 (87.5) & $26(65.7)$ & & \\
\hline Medullary carcinoma & $2(6.3)$ & 5 (14.3) & & \\
\hline ILC & $1(3.1)$ & $5(14.3)$ & & \\
\hline Others & $1(3.1)$ & 0 & & \\
\hline HER2 overexpression & & & & 1.51 \\
\hline No & $30(93.8)$ & $34(97.1)$ & & \\
\hline Yes & $2(6.3)$ & $1(2.9)$ & .502 & \\
\hline Triple negative & & & .244 & 1.46 \\
\hline No & $14(45.2)$ & $22(62.9)$ & & \\
\hline Yes & $17(54.8)$ & $13(37.1)$ & & \\
\hline $\mathrm{NPI}$ & & & .574 & 1.15 \\
\hline$\leq 3.4$ & $2(6.7)$ & $1(3.4)$ & & \\
\hline$>3.4$ & 28 (93.3) & 28 (96.6) & & \\
\hline ER & & & .015 & .195 \\
\hline Negative & $24(75.0)$ & $16(45.7)$ & & \\
\hline Positive & $8(32.0)$ & $19(54.3)$ & & \\
\hline $\mathrm{PgR}$ & & & .093 & 1.02 \\
\hline Negative & $21(67.7)$ & $16(47.1)$ & & \\
\hline Positive & $10(32.3)$ & $18(52.9)$ & & \\
\hline
\end{tabular}

Bold indicates statistically significant.

Unadjusted $P$ values were calculated using the Pearson $\chi^{2}$ test. The Fisher exact test was used to obtain $P$ values where one or more of cells has an expected frequency of 5 or less. Adjusted $P$ values were calculated using the Benjamini-Hochberg false discovery rate method to adjust for multiple testing.

Abbreviations: ER = estrogen receptor; HER2 = human epidermal growth factor receptor 2; IDC-NST = invasive carcinoma of no special type; ILC = invasive lobular carcinoma; NPI = Nottingham Prognostic Index; PgR = progesterone receptor; WRN = Werner protein.

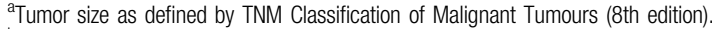

${ }^{\mathrm{b}}$ Grade as defined by Nottingham Grading System. 


\section{Werner Syndrome Protein in Breast Cancer}

Supplemental Table 4 Werner Cytoplasmic Protein Expression in BRCA-Mutated Breast Tumors

\begin{tabular}{|c|c|c|c|c|}
\hline & \multicolumn{2}{|c|}{ Werner Cytoplasmic Protein Expression } & \multicolumn{2}{|c|}{$P$ Value } \\
\hline & Low, N (\%) & High, N (\%) & Unadjusted & Adjusted \\
\hline Tumor size, $\mathrm{cm}^{\mathrm{a}}$ & & & .382 & 1.91 \\
\hline$<1(\mathrm{~T} 1 \mathrm{a}+\mathrm{b})$ & $4(11.8)$ & $1(3.3)$ & & \\
\hline$>1-2(\mathrm{~T} 1 \mathrm{c})$ & $11(32.4)$ & $14(46.7)$ & & \\
\hline$>2-5$ (Т2) & $18(52.9)$ & $13(43.3)$ & & \\
\hline$>5$ (T3) & $1(2.9)$ & $2(6.7)$ & & \\
\hline Tumor stage & & & .148 & 1.48 \\
\hline 1 & $23(63.9)$ & $18(60.0)$ & & \\
\hline 2 & $13(36.1)$ & $9(30.0)$ & & \\
\hline 3 & 0 & $3(10.0)$ & & \\
\hline \multicolumn{5}{|l|}{ Tumor grade ${ }^{b}$} \\
\hline G2 & $7(19.4)$ & $2(6.3)$ & & \\
\hline G3 & $29(80.6)$ & $30(93.8)$ & .157 & 1.41 \\
\hline Vascular invasion & & & .100 & 1.20 \\
\hline No & $17(48.6)$ & $24(74.4)$ & & \\
\hline Probable & $1(2.9)$ & $1(3.2)$ & & \\
\hline Yes & $17(48.6)$ & $6(19.4)$ & & \\
\hline Tumor type & & & .310 & 2.17 \\
\hline IDC-NST & $31(86.1)$ & $23(71.9)$ & & \\
\hline Medullary carcinoma & $3(8.3)$ & 4 (12.5) & & \\
\hline ILC & $1(2.8)$ & $5(15.6)$ & & \\
\hline Others & $1(2.8)$ & 0 & & \\
\hline HER2 overexpression & & & 1.00 & 1.00 \\
\hline No & $34(94.4)$ & 30 (96.8) & & \\
\hline Yes & $2(5.6)$ & $1(3.2)$ & & \\
\hline \multicolumn{5}{|l|}{ Triple negative } \\
\hline No & 19 (54.3) & $17(54.8)$ & & \\
\hline Yes & $16(45.7)$ & $14(45.2)$ & .992 & 1.98 \\
\hline \multicolumn{5}{|l|}{ NPI } \\
\hline$\leq 3.4$ & $3(9.1)$ & 0 & & \\
\hline$>3.4$ & $30(90.9)$ & $26(100.0)$ & .115 & 1.27 \\
\hline \multicolumn{5}{|l|}{ ER } \\
\hline Negative & $24(66.7)$ & $16(51.6)$ & & \\
\hline Positive & $12(33.3)$ & $15(48.4)$ & .210 & 1.68 \\
\hline \multicolumn{5}{|l|}{$\mathrm{PgR}$} \\
\hline Negative & $20(58.8)$ & $17(54.8)$ & & \\
\hline Positive & $14(41.2)$ & $14(45.2)$ & .746 & 2.98 \\
\hline
\end{tabular}

Bold indicates statistically significant.

Unadjusted $P$ values were calculated using the Pearson $\chi^{2}$ test. The Fisher exact test was used to obtain $P$ values where one or more of cells has an expected frequency of 5 or less. Adjusted $P$ values were calculated using the Benjamini-Hochberg false discovery rate method to adjust for multiple testing.

Abbreviations: $\mathrm{ER}=$ estrogen receptor; HER2 = human epidermal growth factor receptor 2; IDC-NST = invasive carcinoma of no special type; ILC = invasive lobular carcinoma; NPI = Nottingham Prognostic Index; PgR = progesterone receptor; WRN = Werner protein.

aTumor size as defined by TNM Classification of Malignant Tumours (8th edition).

${ }^{b}$ Grade as defined by Nottingham Grading System. 
Supplemental Table 5 Correlation Among 5 RECQ Helicases in the Nottingham Tenovus Primary Breast Cancer Series

\begin{tabular}{|c|c|c|c|}
\hline & Low, N (\%) & High, N (\%) & Adjusted $P$ Value ${ }^{a}$ \\
\hline \multicolumn{4}{|l|}{ RECQL1 } \\
\hline RECQL5 & & & $<.001$ \\
\hline Low & 201 (52.6) & $140(37.3)$ & \\
\hline High & $181(47.4)$ & $235(62.7)$ & \\
\hline RECQL4 & & & $<.001$ \\
\hline Low & $245(65.9)$ & $173(50.6)$ & \\
\hline High & $127(34.1)$ & 169 (49.4) & \\
\hline BLM & & & $<.001$ \\
\hline Low & $120(30.7)$ & $71(19.5)$ & \\
\hline High & $271(69.3)$ & $293(80.5)$ & \\
\hline WRN & & & .037 \\
\hline Low & $137(51.7)$ & $113(42.6)$ & \\
\hline High & $128(48.3)$ & $152(57.4)$ & \\
\hline \multicolumn{4}{|l|}{ RECQL4 } \\
\hline RECQL1 & & & $<.001$ \\
\hline Low & $245(58.6)$ & $127(42.9)$ & \\
\hline High & $173(41.4)$ & $169(57.1)$ & \\
\hline RECQL5 & & & $<.001$ \\
\hline Low & $279(57.2)$ & $113(32.7)$ & \\
\hline High & $204(42.8)$ & $233(67.3)$ & \\
\hline BLM & & & .010 \\
\hline Low & $167(32.9)$ & $58(16.6)$ & \\
\hline High & $341(67.1)$ & $291(83.4)$ & \\
\hline WRN & & & $<.001$ \\
\hline Low & 177 (49.7) & $89(38.9)$ & \\
\hline High & $179(50.3)$ & $140(61.1)$ & \\
\hline \multicolumn{4}{|l|}{ RECQL5 } \\
\hline RECQL1 & & $181(43.5)$ & $<.001$ \\
\hline Low & 201 (58.9) & & \\
\hline High & $140(41.1)$ & $235(56.5)$ & \\
\hline RECQL4 & & & $<.001$ \\
\hline Low & $279(71.2)$ & $209(47.3)$ & \\
\hline High & $113(28.8)$ & $233(52.7)$ & \\
\hline BLM & & & $<.001$ \\
\hline Low & $170(37.0)$ & $85(16.5)$ & \\
\hline High & $290(63.0)$ & $429(83.5)$ & \\
\hline WRN & & & $<.001$ \\
\hline Low & 175 (55.2) & $134(37.7)$ & \\
\hline High & $142(44.8)$ & $221(62.3)$ & \\
\hline \multicolumn{4}{|l|}{ BLM } \\
\hline RECQL1 & & & $<.001$ \\
\hline Low & $120(62.8)$ & $271(48.0)$ & \\
\hline High & $71(37.2)$ & $293(52.0)$ & \\
\hline RECQL4 & & & $<.001$ \\
\hline Low & $167(74.2)$ & $341(54.0)$ & \\
\hline High & $58(25.8)$ & $291(46.0)$ & \\
\hline RECQL5 & & & $<.001$ \\
\hline Low & $170(66.7)$ & $290(40.3)$ & \\
\hline High & $85(33.3)$ & $429(59.7)$ & \\
\hline
\end{tabular}




\section{Werner Syndrome Protein in Breast Cancer}

Supplemental Table 5 Continued

\begin{tabular}{|c|c|c|c|}
\hline & Low, N (\%) & High, N (\%) & Adjusted $P$ Value \\
\hline WRN & & & .118 \\
\hline Low & $100(52.6)$ & $236(46.0)$ & \\
\hline High & 90 (47.4) & $233(54.0)$ & \\
\hline \multicolumn{4}{|l|}{ WRN } \\
\hline RECQL1 & & & .037 \\
\hline Low & $137(54.8)$ & $128(45.7)$ & \\
\hline High & $113(45.2)$ & $152(54.3)$ & \\
\hline RECQL4 & & & .010 \\
\hline Low & $177(66.5)$ & $179(56.1)$ & \\
\hline High & 89 (33.5) & $140(43.9)$ & \\
\hline RECQL5 & & & $<.001$ \\
\hline Low & $175(56.6)$ & $142(39.1)$ & \\
\hline High & $134(43.4)$ & $221(60.9)$ & \\
\hline BLM & & & .118 \\
\hline Low & $100(29.8)$ & $90(24.5)$ & \\
\hline High & $236(70.2)$ & $277(75.5)$ & \\
\hline
\end{tabular}

Bold indicates statistically significant.

${ }^{a}$ Adjusted $P$ values were calculated using Benjamini-Hochberg false discovery rate method to adjust for multiple testing. 